\title{
Attention Effects in a High-Frequency World
}

\author{
Bidisha Chakrabarty \\ Pamela C. Moulton \\ Xu (Frank) Wang*
}

December 9, 2015

* Chakrabarty (chakrab@slu.edu) and Wang (xwang9@slu.edu) are at Saint Louis University, and Moulton (pmoulton@cornell.edu) is at Cornell University. We thank Matt Baron, Neil Bhattacharya, Carole Comerton-Forde, Jay Coughenour, Fany Declerck, Stefano DellaVigna, Daniel Dorn, Terry Hendershott, Christine Jiang, Kuan Hui Lee, Laurence Lescourret, Sophie Moinas, Claudia Moise, Christine Parlour, Ryan Riordan, Clara Vega, Brian Weller, Ingrid Werner, Jim Whitworth, Taras Zlupko, and seminar participants at Cornell, the Academy of Behavioral Finance and Economics Meeting, and the Women in Microstructure Meeting for helpful comments. We thank Joey Engelberg for help with news data, Frank Hatheway at NASDAQ OMX for providing the high-frequency dataset, Michael Raines at Wall Street Horizon for providing earnings announcement data, Jake Thornock for sharing EDGAR download data with us, and Taras Zlupko at CRSP for data-related help. 


\title{
Attention Effects in a High-Frequency World
}

\begin{abstract}
How does limited attention affect stock prices in today's computer-driven financial markets? We study this issue by re-examining the effects of limited attention using a dataset that separately identifies trades made by high-frequency traders (HFTs, or computers) versus those made by non-high-frequency traders (human decision-makers). We employ a set of six attention proxies to identify earnings announcements with low investor attention: announcements made on Fridays and on days with multiple earnings announcements, and announcements with slow analyst forecast adjustments, high news distraction, low EDGAR download volume, and low Google search volume. Across multiple attention proxies, we find that HFT trading improves the responsiveness of prices by increasing the short-horizon price response and reducing the long-term price drift following earnings surprises, diminishing the inefficiencies previously observed around low-attention announcements by $69 \%$ to $100 \%$. We find that the price efficiency improvements are more closely tied to HFT liquidity demand than supply, suggesting that HFTs improve efficiency by processing and trading on the information in low-attention announcements.
\end{abstract}

JEL classification: G02, G10, G14, M40, M41

Keywords: Limited attention, high frequency trading, earnings announcements, price efficiency 


\section{Introduction}

A large body of literature documents that limited attention of financial market participants can affect stock pricing through a variety of channels. ${ }^{1}$ DellaVigna and Pollet (2009) posit that on Fridays investors are distracted by the upcoming weekend, which leads them to pay less attention to earnings announcements released on Fridays. As a result, price responses to Friday announcements are less efficient than to earnings announcements made on other weekdays. Hirshleifer, Lim, and Teoh (2009) document similar results for days with multiple earnings announcements and conclude that investors are able to pay less attention to individual earnings announcements on multi-announcement days, which is consistent with limited attention. Chakrabarty and Moulton (2012) identify a different channel - market makers’ limited attention - that affects stock liquidity. They find that on days when stocks assigned to one market maker have earnings announcements, there is a reduction in the liquidity of the non-announcing stocks handled by the same market maker. Together these studies show that decision-makers' limited attention and the need to allocate this scarce resource across competing information sources affect financial market outcomes.

The common motivation for this literature is that human decision-makers' attention is a limited resource. But the direct participation of human decision-makers in the trading process has been diminishing over time. In the past several years, equity markets have witnessed a revolutionary shift in the technology and speed of trading (Jain, 2005). Order submissions and executions now occur in sub-second increments. These are speeds that humans cannot even register, let alone react to. The latest trading hardware (chip) prepares a trade in 740 billionths of a second; by comparison, the blink of an eye takes about one-third of a second. ${ }^{2}$ Technological advances have dramatically increased trading speed, facilitating the proliferation of highfrequency trading, a trading paradigm in which computers trade using algorithms with preprogrammed logic. An estimated 40 to 60 percent of all trades in stocks, derivatives, and foreign currencies across all financial markets can be attributed to high-frequency trading (Sussman, 2012). In the U.S. equity markets, over 50 percent of all trades are such high-frequency trades (Brogaard, Hendershott, and Riordan, 2014). By all measures, high-frequency traders play a large

\footnotetext{
${ }^{1}$ See, e.g., Chakrabarty and Moulton (2012), Corwin and Coughenour (2008), Damadoran (1989), DellaVigna and Pollet (2009), Hirshleifer, Lim and Teoh (2009), and Patell and Wolfson (1982).

${ }^{2}$ For a discussion on recent advances in computerized trading, see http://blogs.wsj.com/marketbeat/2011/06/14/wall-streets-needfor-trading-speed-the-nanosecond-age/.
} 
role in the current trading landscape. Since these machines are not subject to limited attention, we ask: How does limited attention affect stock prices in today's computer-driven markets?

Recent work by DeHaan, Shevlin, and Thornock (2015) provides an interesting segue into this issue. DeHaan et al. (2015) find that attention to earnings announcements is no lower on Fridays than on other days of the week. This result is in contrast to earlier studies by DellaVigna and Pollet (2009) and Damodaran (1989), who document lower attention on Fridays. While DeHaan et al. (2015) do not explore the reasons for this reversal of the previously documented Friday inattention phenomenon, they mention the possibility that the trading technology of modern markets may be at least partially responsible. ${ }^{3}$

In this paper, we test whether attention constraints still matter in a world where highfrequency trading plays a large role. Our study is made possible by a unique dataset that identifies traders as either high-frequency traders (HFTs) or non-HFTs at the trade level. For our empirical setting, we choose corporate earnings announcements because they are events that are generally newsworthy and have been found to attract varying levels of investor attention in prior studies (e.g., DellaVigna and Pollet, 2009; DeHaan et al., 2015). We hypothesize that since attention constraints do not affect HFTs, HFTs should not display the human tendency to ignore lowattention announcements. In fact, the pre-programmed logic of HFT algorithms may benefit from human traders' diminished focus on the low-attention announcements and find more profitable opportunities in these announcements.

Since it is not possible to directly measure how much attention investors pay to an announcement, the literature on attention in financial markets has generated a number of proxies that indirectly measure attention based on trading volume, event characteristics, or investor actions. Studies using volume-based attention metrics (e.g., Corwin and Coughenour, 2008) reason that higher trading volume indicates greater attention and, conversely, lower volume indicates binding attention constraints. This interpretation implicitly assumes that all trading originates from human decision-makers. But since total trading volume in today’s markets arises from HFTs (who trade based on pre-programmed algorithms that are not subject to attention constraints) as well as human decision-makers, volume-based attention proxies may be misleading. Thus we rely on attention proxies that are based on event characteristics or investor actions. Specifically, we use the following non-volume proxies to identify low-attention earnings

\footnotetext{
${ }^{3}$ See DeHaan et al.’s (2015) footnote 4, which alludes to undistracted arbitrageurs and algorithmic traders.
} 
announcements: (1) days on which there are multiple announcements, as in Hirshleifer et al. (2009); (2) announcements after which analysts are slow to incorporate earnings news into their earnings forecasts, as in DeHaan et al. (2015); (3) announcements that are made on Fridays, as in DellaVigna and Pollet (2009); (4) announcements that are accompanied by many non-earningsrelated news stories, which are potentially distracting; (5) announcements that are made on days with lower download volume of financial reports from the Securities and Exchange Commission's (SEC's) Electronic Data Gathering, Analysis, and Retrieval (EDGAR) facility as in DeHaan et al. (2015); and (6) announcements that are accompanied by low Google search volume, as in Da, Engelberg, and Gao (2011). ${ }^{4}$ Because these proxies capture different aspects of the underlying attention phenomenon, we also construct an aggregate attention measure that defines events as low-attention if they are classified as such by many of the individual proxies.

Using this large set of attention proxies, we examine the role of HFT trading on lowattention earnings announcements. Our main hypotheses are that by trading on low-attention earnings announcements, HFTs diminish the previously-documented effects of low attention on stock price efficiency in both the short term and the long term (e.g., DellaVigna and Pollet, 2009; Hirshleifer et al., 2009). We find support for these hypotheses using our aggregate proxy as well as several of the individual proxies. For example, while earnings announcements that occur on days with many announcements generally have short-term cumulative abnormal returns that are significantly less responsive to earnings surprises, this effect is reduced by 69\% when HFTs are active in trading on the low-attention announcements. For the longer horizon, we find that greater HFT participation reduces the post-earnings-announcement drift (PEAD) in prices following low-attention earnings announcements, completely eliminating the PEAD under some lowattention proxies. We also conduct tests using post-close earnings announcements as quasiplacebo events. Post-close announcements are characterized by low investor attention (DeHaan et al., 2015) but do not experience attention-related pricing inefficiencies (Jiang, Likitapiwat, and McInish, 2012). We find no significant effect from HFT trading on the post-close announcements, supporting our interpretation that HFTs' effect is linked to pricing inefficiencies arising on lowattention events, not the low attention itself. In robustness checks, we test small and large stocks separately to show that our results are not simply due to HFTs' preference for large stocks (which typically experience less attention-based inefficiency).

\footnotetext{
${ }^{4}$ Details of the attention proxies and their construction are provided in Section 3.
} 
Finally, we investigate whether the documented improvements in price efficiency arise more from HFTs supplying liquidity to non-HFTs who want to trade on the earnings information or from HFTs themselves incorporating information into prices through their liquidity demand. We find that HFT liquidity demand and supply both account for a larger fraction of total trading on low-attention announcement days. A closer investigation reveals that the improvements in price efficiency are more closely tied to low-attention announcements on which HFTs' liquidity demand relative to their supply is abnormally high. This finding suggests that it is HFTs' ability to process and trade on short-lived information (such as textual news feeds about earnings announcements) that contributes more strongly to the improvement in price efficiency around low-attention earnings announcements.

These findings make several contributions to the literature. First and most important, we advance the study of limited attention into modern financial markets, where high-speed computers are dominant players. We do not claim that limited attention no longer plays any role in financial markets; after all, trading decisions made by humans still account for a large portion of the total trading volume. However, given that in today's markets a significant proportion of trading decisions are made by non-human traders, it is important to understand whether anomalies linked to limited attention are dissipating or disappearing. Our finding that these anomalies are attenuated in an environment with non-human decision-makers (HFTs) implicitly supports the original attribution of these mis-pricings to human attention constraints.

Second, this work is related to recent papers that study how the profitability of anomalies changes over time (e.g., McLean and Pontiff, 2015). Chordia, Subrahmanyam, and Tong (2014) find that several capital market anomalies have attenuated in recent years as market liquidity and trading activity have risen, facilitating more arbitrage activity. ${ }^{5}$ Our study contributes to this literature by showing how the rise of the machines (HFTs), which is both facilitated by and contributes to enhanced liquidity and trading activity, reduces human-attention-based anomalies.

Third, our study suggests that the rise of HFTs has rendered aggregate trading volume a less useful indicator of times when traders are paying less attention. We find that HFTs account for a larger share of trading volume during some low-attention times. Thus researchers using

\footnotetext{
${ }^{5}$ In a similar vein, recent studies find that the declining profitability of the accruals anomaly is attributable to an increase in liquidity (Mashruwala, Rajgopal, and Shevlin, 2006) and a rise in hedge fund trading (Green, Hand, and Soliman, 2011).
} 
trading-volume-based proxies for attention constraints may fail to find significant results because the changes in activity levels of HFTs and non-HFTs may (at least partially) offset each other.

Finally, our study contributes to the literature on high-frequency trading and price efficiency. We show that HFTs play a beneficial role in making prices more efficient around lowattention events, times when stocks have been shown to have particularly inefficient price responses. This result complements the existing literature on high-frequency trading, which catalogs several ways in which HFTs can lead to better market quality in general, including improved liquidity, lower transactions costs, and greater price efficiency. With the advent of "big data” in modern financial markets, the role of machines in both aiding and displacing humans in the trading process has attracted increasing attention and in some cases alarm (Hope, 2015). To the best of our knowledge this study is the first to examine the interplay between greater automation of trading and limited investor attention.

The remainder of the paper is organized as follows. Section 2 provides background on high-frequency traders, discusses the role of attention in financial markets, and develops our hypotheses. Section 3 describes our sample, data sources, and key trading and attention measures. Section 4 presents our tests of whether HFTs reduce the effects of investor inattention on lowattention earnings announcements. Section 5 presents our tests of HFT trading on post-close earnings announcements. Section 6 investigates how HFTs affect price efficiency. Section 7 presents robustness checks, and Section 8 concludes. Appendix A defines all of our variables. Appendix B presents an illustration of how our HFT trading measures are calculated.

\section{High frequency trading, attention, and hypotheses}

We first discuss the institutional background on high-frequency trading and its role in financial markets. We then discuss the role of human attention constraints in markets. Finally, we bring together the insights of both streams of the literature to develop our testable hypotheses.

\subsection{HFT: Definition, growth, and effects}

The SEC’s Concept Release on Equity Market Structure (2010) recognizes that highfrequency trading is one of the most significant market structure developments in recent years. It notes that, "[b]y any measure, HFT is a dominant component of the current market structure and 
likely to affect nearly all aspects of its performance." Although there is no strict definition of high-frequency trading, the following characteristics are generally attributed to it (SEC, 2014): ${ }^{7}$

- Use of high speed, sophisticated algorithms for generating, routing, executing and/or canceling orders.

- Use of co-location services and individual data feeds offered by exchanges and vendors to minimize network and other latencies.

- Very short timeframes for establishing and liquidating positions.

- High volume order submission followed in quick succession by cancellations.

- Ending the trading day in as close to a flat position as possible (that is, not carrying significant overnight positions).

High-frequency trading began in early 2000 and has grown rapidly to become a dominant player in today's markets. In U.S. equities, estimates of high-frequency trading come mainly from two private research firms: Rosenblatt Securities and the Tabb Group. Estimates from Rosenblatt Securities indicate that about 67\% of all domestic stock trades between 2008 and 2011 were executed by HFTs, a figure that may have declined to about $50 \%$ by the end of $2014 .{ }^{8}$ In terms of volume, HFTs accounted for a trading volume of about 3.25 billion shares per day in 2009; that figure stood at about 1.6 billion shares per day by 2012. The Tabb Group estimates that highfrequency trading revenue was about $\$ 7.2$ billion in 2009. ${ }^{9}$

The growth of high-frequency trading has attracted increasing focus from regulators, the media, and academic researchers. The 2010 SEC concept release on equity market structures (SEC, 2010), the Foresight Project on the Future of Computer Trading in Financial Markets (BIS, 2011), and the MiFID II proposal are all regulatory efforts to understand the impact of high-frequency trading's growth on market quality. In one of the first academic studies to examine the impact of HFTs on market quality, Hendershott, Jones, and Menkveld (2011) find that algorithmic trading improves several measures of market liquidity - reducing spreads, reducing adverse selection, and enhancing the informativeness of quotes. Hasbrouck and Saar (2013) find similar evidence of

\footnotetext{
${ }^{6}$ Securities Exchange Act Release No. 34-61358, 75 FR 3594, 3606 (January 21, 2010) (“Concept Release”).

7 The first two characteristics can also apply to sophisticated non-HFT traders, such as institutional traders using smart orderrouting technology to optimize their order executions. It is the last three characteristics that distinguish HFTs in particular.

${ }^{8}$ Matthew Philips, "How the Robots Lost: High-Frequency Trading's Rise and Fall,” Bloomberg BusinessWeek, June 6, 2013, available at http://www.businessweek.com/articles/2013-06-06/how-the-robots-lost-high-frequency-tradingsrise-and-fall.

${ }^{9}$ Larry Tabb, "No, Michael Lewis, the US Equities Market Is Not Rigged," TABB Group, March 31, 2014, available at http://blogs.wsj.com/moneybeat/2014/04/01/larry-tabb-no-mr-lewis-the-markets-are-not-rigged/
} 
reduced spreads, higher depths, and lower short-term volatility associated with HFTs' trades. Brogaard et al. (2014) find that HFTs improve price discovery in U.S. equities, a finding that Chaboud, Chiquoine, Hjalmarsson, and Vega (2014) confirm for the foreign exchange market, where increased HFT activity reduces arbitrage opportunities and return autocorrelations.

In contrast to these positive effects, some recent studies suggest that HFT activity may not be an unmitigated blessing. In examining the Flash Crash of May 2010, Kirilenko, Kyle, Samadi, and Tuzun (2014) find that although HFTs did not trigger the crash, they exacerbated price movements that day. Biais, Foucault, and Moinas (2015) build a theoretical model which shows that high levels of HFT activity can generate market exclusion for slower traders and create negative externalities. Biais and Woolley (2011) discuss the practice of quote stuffing by HFTs, wherein large volumes of quotes are placed with the intent not to trade but to quickly cancel these quotes, thereby slowing down public data dissemination. In sum, the net effect of how HFTs affect markets is yet to be established. Amidst this ongoing debate on the impact of HFTs, this study focuses on an unexplored issue surrounding HFTs: whether and how the effects of limited attention have changed with the rise of high-speed machine trading.

\subsection{Investor attention in financial markets}

Limited attention is a human attribute, and historically the primary decision-makers in financial markets have been human traders, including institutional portfolio managers, individual (retail) investors, and human market makers such as specialists. A large body of research documents the effects of attention as a scarce cognitive resource in economic decisions (Kahneman, 1973). For example, studies show that limited cognitive capacities can explain the use of heuristics in decision-making (Gabaix, Laibson, Moloche, and Weinberg, 2006) and underreaction to information (Hong and Stein, 1999). Bali, Peng, Shen, and Tang (2014) find that limited investor attention drives long-term return predictability following liquidity shocks. Such underreaction has asset pricing consequences and leads to predictable price patterns, including reduced speed of price adjustment (Peng, 2005), prices that do not fully impound all available public

information (Huberman and Regev, 2001), under-reaction to earnings announcements (Hirshleifer et al., 2009), and failure to fully respond to profits and losses disclosed in corporate communications (Balakrishnan, Bartov, and Faurel, 2010).

The delay in processing, or under-reaction to, information as a result of limited attention becomes especially prominent when there are attention-grabbing events or when multiple stimuli 
demand attention. Barber and Odean (2008) find that investors more frequently buy stocks that come to their attention due to news announcements, ignoring non-news-making investment opportunities. In the context of price limit hits - an attention-grabbing event - on the Shanghai Stock Exchange, Seasholes and $\mathrm{Wu}$ (2007) find that the attention of individual investors, particularly first-time buyers, is attracted when price limits are hit. Graham and Kumar (2006) find that certain investors tend to trade securities following specific events that attract attention, such as dividend initiations. Lee (1992) directly infers that small investors' buy decisions are associated with news events that bring these securities to their attention.

Earnings announcement days are times of increased information in the markets (Beaver, 1968; Brown, Hillegeist, and Lo, 2009; Engelberg, McLean, and Pontiff, 2015), and stocks with earnings announcements generally attract more attention (Aboody, Lehavy, and Trueman, 2010). Hence, several studies examine hypotheses regarding limited attention in the context of earnings announcements. Hirshleifer et al. (2009) examine days with multiple earnings announcements and find that the immediate stock price and volume reactions to a firm's earnings surprise is weaker, and post-earnings announcement drift is stronger, when a greater number of earnings announcements by other firms are made on the same day. Chakrabarty and Moulton (2012) find that market makers' limited attention leads to lower liquidity for stocks when other stocks covered by the same market maker have earnings announcements.

DeHaan et al. (2015) find that managers try to take advantage of predictable variations in attention by releasing bad news in periods of low attention. The issue of strategically timing news to exploit expected patterns of attention constraints is also explored by DellaVigna and Pollet (2009), who find that Friday earnings announcements have a lower immediate stock price response and a higher delayed response in addition to a lower abnormal volume response than non-Friday announcements. Patell and Wolfson (1982) and Damodaran (1989) find that worse earnings news tends to be released on Fridays and after regular trading hours.

\subsection{Hypotheses}

We build on the literature that finds reduced trader participation and differences in price efficiency for low-attention versus high-attention earnings announcements. Our null hypothesis is that HFTs have no marginal effect on price efficiency for low-attention announcements. Our alternative hypotheses derive from the logic underpinning the attention literature to date: that human traders have limited attention or cognitive capacity and therefore tend to under-react to 
certain earnings announcements. In contrast, we would not expect HFTs, which trade based on pre-programmed computer algorithms, to suffer from human attention constraints. Furthermore, the growing HFT literature suggests that HFT trading leads to faster incorporation of information into prices (e.g., Brogaard et al., 2014), and HFT algorithms are known to parse textual news such as earnings announcements from pre-processed news feeds (e.g., Gross-Klussman and Hautsch, 2011; Beschwitz, Keim, and Massa, 2015). In our context, this suggests that HFTs trading when human traders are distracted around low-attention events should induce more efficient price reactions. This leads to our first hypothesis:

H1: Following low-attention earnings announcements, stocks with high-frequency trading should experience more efficient short-term price reactions than those without highfrequency trading.

If HFTs increase short-term price efficiency by incorporating more earnings-related information into prices, they may also reduce the long-term price drift associated with lowattention earnings announcements. For example, Hirshleifer et al. (2009) show that low-attention events with less efficient short-term price response tend to experience larger long-term price drifts. This leads to our second hypothesis:

H2: Following low-attention earnings announcements, stocks with high-frequency trading should experience more efficient long-term price reactions (reduced post-earningsannouncement drift) than those without high-frequency trading.

\section{Sample, data, and measures}

In this section we discuss our sample and the construction of our high-frequency trading variables and attention proxies. Appendix A details all of our variable definitions, calculations, and data sources.

\subsection{Sample construction}

Our key data on HFT and non-HFT trading are obtained from a dataset provided by NASDAQ. ${ }^{10}$ The NASDAQ dataset includes 120 stocks, selected through a stratified random sampling procedure to reflect the dispersion in market capitalization of the universe of all firms

\footnotetext{
${ }^{10}$ This dataset has been used in other academic studies e.g., Brogaard et al. (2014) and Carrion (2013). It is provided under a nondisclosure agreement.
} 
listed on NASDAQ and NYSE. The sample includes all trades in these stocks that occur on the NASDAQ exchange in 2008 and 2009.

IBES and Compustat are the two most widely used databases to identify earnings announcement dates. We begin with the NASDAQ sample of 120 stocks, identify their earnings announcements dates from IBES, and match these announcements in Compustat. This gives us 960 announcements, 937 (98\%) of which have the same date in both databases. We delete two announcements where the dates in the two databases are more than 30 days apart. For the remaining 21 announcements, we verify the correct announcement date manually by examining company press releases and newswire reports. This gives us a sample of 958 earnings announcements (937 initially matched plus 21 verified by news sources).

Recent work by DeHaan et al. (2015) suggests that mixed results in the earnings literature may be attributed to challenges in identifying the precise time of announcements. Bradley, Clarke, Lee, and Ornthanalai (2014) find that IBES timestamps are not always accurate. Since our study relies on announcement times in addition to their dates, we use two additional sources to verify the announcement times: Wall Street Horizon (WSH), which provides institutional traders with corporate event data, and Factiva, a leading source for business newswires.

Of the 958 announcements in our sample, 781 (82\%) have the same date and time in WSH and IBES/Compustat. There are nine earnings announcements that are either not covered by WSH or have different dates in WSH and IBES/Compustat. We verify the date for these announcements using Factiva. For another 168 announcements, the dates match in WSH and IBES/Compustat but the reported times differ by one minute or more. For these cases we use Factiva to verify the announcement time. For 130 of these announcements Factiva agrees with the WSH or IBES/Compustat time, and we use that time. For the remaining 38 announcements, we use the earliest timestamp among Factiva, WSH, and IBES/Compustat as the announcement time. We thus arrive at timestamps for all 958 of the earnings announcements in the sample as filtered so far.

We impose the following additional filters to arrive at our final sample: (i) exclude one announcement made on a non-trading day; (ii) exclude two announcements with no trading in the NASDAQ dataset; (iii) exclude four stocks with no trading after announcement time on any of their earnings announcement dates; (iv) exclude 13 stocks that have no HFT trading after announcement time on any of their announcement dates; (v) exclude 75 announcements with no trades after their announcement time. After imposing these filters, we are left with 103 stocks and 
745 earnings announcements. These 103 stocks have over 542 million trades, for a total volume exceeding 105 billion shares and a dollar volume of about \$3.9 trillion in 2008-2009.

\subsection{HFT measures}

Each trade is the result of the interaction between two counterparties, one of which demands liquidity (a marketable order that immediately takes liquidity from the opposite side of the order book) and the other which supplies liquidity (the limit order that is sitting in the order book). NASDAQ identifies the liquidity demander and supplier in each trade as a high-frequency trader $(\mathrm{H})$ or non-high-frequency trader $(\mathrm{N})$. NASDAQ attaches the HFT and non-HFT identifiers based its information about the identity of each trader (which is not publicly disseminated). NASDAQ makes this determination based on the firms' trading styles and also on the firms' website descriptions. The characteristics of firms that have been identified as HFTs generally follow the SEC's identification of HFTs, as outlined in Section 2.1.

For each trade, in addition to ticker symbol, date, time (at the millisecond level), price, share volume, and buy/sell indicator, NASDAQ provides one of four possible trader-type classifications:

- HH: Both the liquidity demander and supplier for the trade are HFTs;

- $\quad \mathrm{HN}$ : The liquidity demander is an HFT, the liquidity supplier is a non-HFT;

- $\quad \mathrm{NH}$ : The liquidity demander is a non-HFT, the liquidity supplier is an HFT; and

- $\quad \mathrm{NN}$ : Both the liquidity demander and supplier for the trade are non-HFTs.

From these classifications we construct three measures of HFT trading and two measures of the interactions between HFTs and non-HFTs. ${ }^{11}$ Our first measure, HFT ${ }^{\text {All }}$, captures the percentage of daily share volume that HFTs represent in each stock each day, taking into account both sides of each trade (liquidity demand and liquidity supply). It is calculated as:

$$
\mathrm{HFT}^{\mathrm{All}}=(2 * \mathrm{HH}+\mathrm{HN}+\mathrm{NH}) /(2 * \text { Total Volume }) \text {, }
$$

The numerator in Equation (1) captures the shares demanded and supplied by HFTs, and the denominator reflects the total number of shares demanded and supplied in total (which is equal to two times volume, since each trade involves a demander and a supplier). ${ }^{12}$

\footnotetext{
${ }^{11}$ Our HFT measures are similar to those used in other HFT studies (e.g., Brogaard et al., 2014, and Carrion, 2013). Because of market clearing, HFT and non-HFT trading in each category (overall, demand, and supply) sum to 100\%, so non-HFT trading percentages are simply $100 \%$ - HFT trading percentages.

12 We obtain qualitatively similar results using the HFT participation variable defined as $(\mathrm{HH}+\mathrm{HN}+\mathrm{NH}) /$ Total Volume, as in Carrion (2013).
} 
Our next two measures capture the extent to which HFTs demand and supply liquidity in each stock. They are calculated as:

$$
\begin{aligned}
& \mathrm{HFT}^{\mathrm{D}}=(\mathrm{HH}+\mathrm{HN}) / \text { Total Volume }, \\
& \mathrm{HFT}^{\mathrm{S}}=(\mathrm{HH}+\mathrm{NH}) / \text { Total Volume } .
\end{aligned}
$$

Finally, we create two measures of the interaction between HFTs and non-HFTs, distinguishing between which trader type is demanding versus supplying liquidity in these interactions. They are calculated as follows:

$$
\begin{aligned}
& \mathrm{HN} \%=\mathrm{HN} / \text { Total Volume }, \\
& \mathrm{NH} \%=\mathrm{NH} / \text { Total Volume } .
\end{aligned}
$$

Panels A and B of Table 1 present descriptive statistics for our sample stocks and HFT trading, demand, and supply as well as interaction measures for these stocks. The cross-sectional statistics in Panel A show that the sample of stocks is diverse; this is by design, as NASDAQ intentionally provides these data on a sample of stocks evenly spread across the different market capitalizations. Over the two-year sample period, nearly all of the stocks have eight regular earnings announcements (mean number of announcements is 7.98). Panel B shows that HFTs represent $28.8 \%$ of trading volume on average. Consistent with prior literature (e.g., Carrion, 2013), we find that total HFT demand (32.8\%) exceeds supply (24.7\%). When trading with nonHFTs, HFTs are more often on the liquidity demanding side (24.9\%) than on the liquidity supplying side (16.8\%).

\section{[Table 1 here]}

\subsection{Attention proxies}

To test our hypotheses we need to identify low-attention earnings announcements. We employ six non-volume-based proxies for low attention derived from the prior literature. ${ }^{13,14}$

Our first proxy for low-attention earnings announcements is those that occur on the same day that many other earnings announcements are released, dubbed "busy” days. Hirshleifer et al. (2009) find that investors tend to underreact to earnings announcements released on a busy day.

\footnotetext{
${ }^{13}$ We note that these six proxies are not necessarily independent of each other, but rather are related measures designed to capture the underlying phenomenon of low investor attention. We examine their correlation at the end of this section.

${ }^{14}$ We do not use earnings announcements that are released after the market close as a proxy for low attention because Jiang et al. (2012) and Michaely et al. (2014) find that earnings announcements made after the market close have more efficient price reactions and a high degree of informational efficiency. We use post-close announcements as a quasi-placebo sample to differentiate between investor inattention in general and investor inattention that is associated with pricing inefficiencies (see Section 6).
} 
Our second proxy for low-attention earnings announcements is those with slow analyst speed, as in DeHaan et al. (2015). Analyst speed is the speed (inverse of day count) with which analysts incorporate earnings news into their forecasts. We collect from IBES all analyst forecast updates within 30 days of a firm's earnings announcement. Following DeHaan et al. (2015), we then calculate the number of weekdays between the earnings announcement and each analyst forecast update $(j)$, take the average, and calculate the analyst updating speed as:

$$
\text { AnalystSpeed }=-1 * \ln \left(\frac{1}{j} \sum_{j=1}^{J}[1+\text { Weekdays until forecast update } j]\right) \text {. }
$$

Our third proxy for low-attention earnings announcements is those that occur on a Friday, when traders may be distracted by the upcoming weekend (DellaVigna and Pollet, 2009).

Our fourth low-attention proxy is a measure of news distraction. We posit that just as investors may be distracted when there are many different firms announcing earnings on the same day (Hirshleifer et al., 2009), investors may also be distracted from a firm's earnings announcement when there are many non-earnings-related stories about the same firm on the same day as the earnings announcement. Firms may recognize this potential distraction: Miller (2002) finds that firms strategically release other discretionary disclosures with their earnings news. From Dow Jones Newswires (via Factiva), we hand-collect the number of new stories for each firm on each of its earnings announcement days, and within those we also count the number of stories that are specifically about the firm's earnings announcement. We define news distraction as the number of stories about a firm that are not about the firm's earnings.

Our fifth proxy for low-attention earnings announcements is low volume of downloads of financial filings from the SEC's EDGAR online system, which hosts financial filings by public companies. ${ }^{15}$ DeHaan et al. (2015) find that abnormal EDGAR download volume is a good proxy for investor attention. Similar to DeHaan et al. (2015), we compute abnormal EDGAR download volume as follows:

$$
E D G A R \text { downloads }=\ln \left(E D G A R_{t}\right)-\ln \left(\frac{1}{5} \sum_{w=1}^{5} E D G A R_{w}\right),
$$

where the first term is the natural log of EDGAR download volume on the day of interest, and the second term is the natural log of the average EDGAR download volume for the same weekday over the prior five weeks.

\footnotetext{
15 The EDGAR download data are analyzed in Drake, Roulstone, and Thornock (2014), and we thank the authors for sharing the data with us.
} 
Our sixth proxy for low-attention earnings announcements is low Google search volume. Prior research shows that the search frequency in Google (the Search Volume Index, abbreviated SVI) is a good proxy for investor attention (e.g., Da et al., 2011; DeHaan et al., 2015). Drake et al. (2012) document that in the two weeks preceding an earnings announcement, the SVI measure shows a significant increase, and they interpret that as increased investor attention and demand for information. To construct our Google SVI variable, we proceed as follows. From Google Trends, we obtain the daily and weekly SVI values for each stock in our sample. We use tickers instead of company names as our search terms to ensure that we capture results that relate to the search for financial information for a firm (Da et al., 2011). The SVI numbers are ranked values that denote the relative popularity of a search term in the period (day or week) of the query. Google does not provide the raw search numbers for any search term; instead it first normalizes the raw search values by the overall internet search volume (popularity of that term vis-à-vis all other search terms) and then scales the normalized numbers by the highest value of the search term in the period. The normalization and scaling of the SVI numbers complicate comparison of these numbers across periods, as illustrated by Madsen and Niessner (2014). To make daily SVIs comparable across months, we follow Madsen and Niessner's adjustment procedure and scale the daily SVIs (SVId) with the weekly SVIs $\left(\mathrm{SVI}_{\mathrm{w}}\right)$ as follows:

$$
\mathrm{SVI}=\mathrm{SVI}_{\mathrm{d}} * \mathrm{SVI}_{\mathrm{w}} / 100 \text {. }
$$

We use the natural log of $(1+\mathrm{SVI})$ as our Google search volume variable. Following the literature, we exclude tickers that are common words (e.g., COST and GAS), as their search volume is inflated by searches unrelated to the stock of interest; this filter removes 12 sample firms. For an additional 33 of our sample tickers Google Trends returns no results because of sparse search volume. This is a common issue in research using the SVI measure. For example, only 56\% of the firm-week observations in Da et al.’s (2011) Russell 3000 stock sample have a non-null SVI. In total, we are able to calculate the SVI measure for 58 of our 103 sample stocks (about 56\% of our sample stocks). Thus our sample size is severely reduced when we use the Google search volume to proxy for limited attention.

Panel C of Table 1 presents descriptive statistics for our six attention proxies. Of the 745 earnings announcements in our sample, 60 (8\%) occur on Fridays, similar to the 7.6\% DeHaan et al. (2015) find in their sample of earnings announcements from 2000 to 2011. On average there are about 233 other earnings announcements on the day that one of our sample earnings 
announcements occurs, and the standard deviation of 152 announcements is large. The average time between an earnings announcement and the average analyst forecast update is 3 trading days, with a median of 1.3 days and a standard deviation of 4.4 days. The resulting analyst speed measure has a mean of -1.04 with a standard deviation of $0.74 .{ }^{16}$ For comparison, DeHaan et al. (2015) report mean analyst speed of -0.96 and standard deviation of 0.54 for their sample. The average firm has 1.95 non-earnings news stories on earnings announcement days, with a standard deviation of 3.68. There are an average of 137 financial forms downloaded from the SEC's EDGAR database daily, with a standard deviation of 175 . The Google search volume index also displays wide variations over our sample of earnings announcements.

We do not expect the six attention proxies to be independent of each other, as they are all related to the same underlying phenomenon of investor attention. Thus a natural question is whether the six attention proxies all identify the same earnings announcements as low-attention events. One of the proxies is a straight indicator: earnings announcements that occur on Fridays are considered low-attention, and those on non-Fridays are not. For the other proxies, we designate earnings announcements as low-attention if the value of the proxy is above or below (depending on the measure) the median of the measure for all earnings announcements within the quarter. ${ }^{17}$ For example, if the median number of earnings announcements per day is 200 in the first quarter of 2008, all earnings announcements in that quarter that occur on days with more than 200 announcements are designated as low-attention under the Busy Day measure. Table 2 displays the pairwise correlations between announcements identified as low-attention by the six attention proxies.

\section{[Table 2 here]}

While several of the pairwise correlations are significant, most are below 10\%, suggesting that the six proxies for low attention capture different aspects of attention. For example, lowattention announcements under the Busy Day measure are uncorrelated with those identified under the Slow Analyst Speed measure (correlation of -0.022, $p$-value of 0.581), showing that slow analyst updates are not merely due to a heavy load of announcements all being released on the same day. The negative correlation between proxies such as Friday and Busy Day are not

\footnotetext{
${ }^{16}$ Because the analyst speed measure is a nonlinear (in this case, logarithmic) transformation of the number of days, it is not possible to convert directly between the mean number of days and mean analyst speed, so we report both in the table.

${ }^{17}$ Low attention is determined by above-median number of multiple earnings announcements or news distraction, or belowmedian analyst speed, EDGAR downloads, or Google SVI measure.
} 
surprising, given the small number of Friday announcements in recent years (e.g., DeHaan et al., 2015). The insignificant correlations between Google search volume and the other attention proxies are likely due to the large number of announcements for which the Google SVI variable cannot be calculated.

To capture these different aspects of attention jointly, we construct an Aggregate lowattention proxy using five of our six attention metrics. We exclude Google SVI from the Aggregate measure because the large number of missing observations for Google SVI severely limits the sample size. To construct our Aggregate low-attention metric we proceed as follows. First, we calculate how many of the remaining five proxies identify each earnings announcement as lowattention (so each announcement has an Aggregate score that can range from zero to five, with a score of five meaning that the announcement is labeled low-attention according to all five proxies). Second, within each quarter, we designate all of the announcements that have an Aggregate score above the quarterly median as low-attention announcements. For example, Honeywell's earnings announcement on July 18, 2008, is categorized as low-attention by the analyst speed, Friday, and news distraction proxies, giving it an Aggregate score of three. Since this is above the median Aggregate score of two in the third quarter of 2008, the July 18, 2008 Honeywell announcement is marked as low-attention under the Aggregate measure.

\section{High-frequency trading and price efficiency}

Our hypotheses are that high-frequency trading is associated with more efficient price reactions around low-attention earnings announcements. We examine both the immediate price response and the long-term price drift, since the literature finds both a lower immediate price response and higher post-earnings-announcement drift for low-attention earnings announcements (e.g., DellaVigna and Pollet, 2009; Hirshleifer et al., 2009).

\subsection{Immediate price response}

Distraction or low attention has been shown to reduce investor reaction (short-term cumulative abnormal returns) to earnings surprises. If HFTs step in and trade during low-attention periods, their actions should attenuate this inefficient response of stock prices to earnings announcements. We ask whether low-attention earnings announcements with HFT trading 
experience more efficient reactions to earnings surprises than similar earnings announcements without HFTs.

We begin with the Aggregate measure of low attention, and then test each attention measure separately with the exception of the Friday low-attention proxy. We are unable to test the Friday low-attention proxy separately because HFTs trade on all but one of the Friday earnings announcements, providing too little variation to examine. ${ }^{18}$ We run regressions of the following form:

$$
\begin{aligned}
\text { CAR }_{i, t, t+1}=\alpha & +\beta_{1} \text { LowAttn }_{i, t}+\beta_{2} \operatorname{HighUE}_{i, t}+\beta_{3} \operatorname{HFT}_{i, t} \\
& +\beta_{4} \operatorname{LowAttn}_{i, t} \cdot \operatorname{HighUE}_{i, t}+\beta_{5} \operatorname{LowAttn}_{i, t} \cdot \operatorname{HFT}_{i, t}+\beta_{6} \operatorname{HighUE}_{i, t} \cdot H F T_{i, t} \\
& +\beta_{7} \operatorname{LowAttn}_{i, t} \cdot \operatorname{HighUE}_{i, t} \cdot \operatorname{HFT}_{i, t} \\
& +\sum_{j=1}^{J} \gamma_{j} \text { Control }_{j, i, t}+\sum_{j=1}^{J} \delta_{j} \text { Control }_{j, i, t} \cdot \operatorname{HighUE}_{i, t}+\varepsilon_{i, t},
\end{aligned}
$$

where $C A R_{i, t, t+1}$ is the two-day cumulative abnormal return for stock $i$ from earnings announcement day $t$ to day $t+1$; LowAttn $i, t$ is equal to one if the earnings announcement falls into the low-attention category given the proxy being used, else zero; HighUE $E_{i, t}$ is equal to one if the announcement has above-median unexpected earnings, else zero. ${ }^{19}$ Unexpected earnings is computed as (Earnings Analyst consensus forecast) / Price, as in DeHaan et al. (2015), DellaVigna and Pollet (2009), and Hirshleifer et al. (2009). ${ }^{20} H F T_{i, t}$ is equal to one if there is HFT trading following the earnings announcement on day $t$, else zero. ${ }^{21}$ Control $_{j, i, t}$ includes market capitalization and earnings surprise volatility over the prior four years (both as in DellaVigna and Pollet, 2009). We also include month and year indicators to control for differences in return sensitivity across quarters and within a quarter. All controls are interacted with HighUE $E_{i, t}$, and standard errors are clustered by announcement day to control for correlation of returns on the same day.

The main estimate of interest is the coefficient on the three-way interacted term LowAttn $_{i, t} * H i g h U E_{i, t} * H F T_{i, t}$. This coefficient captures the marginal effect of HFTs on the response

\footnotetext{
${ }^{18}$ We note that this lack of variability is caused by HFTs trading (rather than HFTs not trading) during these low-attention earnings events, which is in itself consistent with our conjecture that HFTs are less likely to be distracted from trading on Fridays.

${ }^{19}$ Our limited sample size precludes using the finer quantile distinctions of earlier studies, which had the benefit of larger samples.

${ }^{20}$ Kothari (2001) points out that analyst forecasts are believed to be "a better surrogate for the market's expectations than timeseries forecasts" (page 153).

${ }^{21}$ For example, if stock $i$ has an earnings announcement at 10:00 am on day $t$, the variable $H F T_{i, t}$ is equal to one if stock $i$ has any trades involving HFT between 10:00 am and midnight on day $t$, else zero. Using a fixed two-hour period after the announcement, rather than the rest of the day, yields identical inference; see robustness checks in Section 7.
} 
of the cumulative abnormal return to high unexpected earnings in low-attention earnings announcements. Our first hypothesis predicts that the presence of HFTs increases short-term price efficiency, meaning that cumulative abnormal returns are more responsive to unexpected earnings, all else equal. This predicts a positive coefficient on the three-way interacted term. Table 3 presents the regression results.

\section{[Table 3 here]}

The results for the aggregate attention proxy, in the first column, provide support for our hypothesis. The coefficient estimate for the triple interaction term LowAttn*HighUE*HFT is positive (0.173) and significant ( $p$-value <0.001), indicating that earnings announcements identified as low-attention by the aggregate metric have greater short-term stock price response to earnings surprises when they have HFT trading. The negative marginal effect of low attention without HFT (the coefficient of -0.165 on LowAttn*HighUE) is consistent with the findings in the previous literature that earnings surprises during low-attention times garner lower short-term stock

price responses, as distracted investors under-react to earnings surprises. Figure 1 graphs the marginal effects with and without HFT trading from Table 3.

[Figure 1 here]

Figure 1 shows that in general, the presence of HFTs attenuates the effect of low-attention on earnings announcements, reducing the under-reaction that occurs on low-attention announcements without HFTs. The effect is statistically significant for the aggregate, busy day, slow analyst speed, and low EDGAR download attention proxies, with the reductions ranging from $69 \%$ for the busy day proxy (dividing the marginal HFT effect, LowAttn*HighUE*HFT, by the classic attention effect without HFTs, LowAttn*HighUE, or 0.066/-0.095 = -69\%) to over 100\% for the aggregate proxy. Results for the high news distraction and low Google search proxies are insignificant. Statistical power of the tests to detect significance is likely the main problem for the Google search proxy, as Google search volume is available for only 56\% of our sample stocks.

\subsection{Long-term price drift}

The results documented in the previous section suggest that the participation of HFTs in trading on low-attention earnings announcements tempers the inefficiency in short-term price responses to unexpected earnings, consistent with our first hypothesis. Our second hypothesis predicts that the greater efficiency of short-term price responses leaves less scope for a longer- 
term price drift for low-attention earnings announcements with greater HFT participation. To test this, we estimate regressions of the form:

$$
\begin{aligned}
\text { CAR }_{i, t+2, t+45} & =\alpha+\beta_{1} \operatorname{LowAttn}_{i, t}+\beta_{2} \operatorname{HighUE}_{i, t}+\beta_{3} \operatorname{HFT}_{i, t} \\
& +\beta_{4} \operatorname{LowAttn}_{i, t} \cdot \operatorname{HighUE}_{i, t}+\beta_{5} \operatorname{LowAttn}_{i, t} \cdot \operatorname{HFT}_{i, t}+\beta_{6} \operatorname{HighUE}_{i, t} \cdot \operatorname{HFT}_{i, t} \\
& +\beta_{7} \operatorname{LowAttn}_{i, t} \cdot \operatorname{HighUE}_{i, t} \cdot \operatorname{HFT}_{i, t} \\
& +\sum_{j=1}^{J} \gamma_{j} \text { Control }_{j, i, t}+\sum_{j=1}^{J} \delta_{j} \text { Control }_{j, i, t} \cdot \operatorname{HighUE}_{i, t}+\varepsilon_{i, t}
\end{aligned}
$$

where $C A R_{i, t+2, t+45}$ is the cumulative abnormal return for stock $i$ from day two to day 45 after the earnings announcement (the post-earnings-announcement drift, or PEAD), and all other variables are as defined in equation (9). As before, the main coefficient of interest is the coefficient $\beta_{7}$ on the three-way interacted term $\operatorname{LowAttn}_{i, t} * H i g h U E_{i, t} * H F T_{i, t}$. In this specification, $\beta_{7}$ captures the marginal effect of HFTs on the post-earnings-announcement drift after low-attention earnings announcements with high earnings surprises. Our second hypothesis predicts that the presence of HFTs increases price efficiency, meaning price drift should be reduced when HFTs trade on lowattention earnings announcements with earnings surprises. Therefore, all else equal, we expect a negative coefficient on the three-way interacted term. Table 4 presents the regression results.

\section{[Table 4 here]}

The results for our aggregate low-attention proxy, in the first column, provide support for our second hypothesis. For earnings announcements categorized as low attention under the aggregate measure, the coefficient estimate on our main variable of interest, the triple interaction term of LowAttn*HighUE*HFT, is negative and significant (coefficient of -0.208 with a p-value $<0.001$ ). This indicates that when HFTs trade on earnings announcements that are made on days with low aggregate attention and also have a surprise component, the subsequent PEAD is significantly lower. The aggregate PEAD results are driven strongly by busy-day and slow-analystspeed earnings announcements (as in the short-term price efficiency analyses of Table 3) as well

as high-news-distraction and low-EDGAR-download announcements. As in the short-term price reaction results (Table 3), the results for the low Google search volume proxy are not significant. Figure 2 graphs the marginal effects with and without HFT trading from Table 4.

[Figure 2 here] 
Figure 2 shows that the presence of HFTs generally attenuates the effect of low attention on PEAD following earnings announcements with high earnings surprises. Among the five attention proxies with statistically significant effects, the reductions range from $79 \%$ for the high news distraction proxy to more than $100 \%$ for slow analyst speed. Overall, these PEAD results combined with the short-term price reaction results in Table 3 suggest that when HFTs are involved in trading on low-attention earnings announcements, both the immediate price under-reaction to earnings surprises and post-earnings-announcement drift are reduced, consistent with our second hypothesis.

\section{Post-close earnings announcements}

The intuition behind our hypotheses is that HFTs reverse the inefficient price reactions of attention-constrained human traders, and our empirical results so far largely support this premise. But another possibility is that HFTs always lead to higher immediate and lower long-term responses to earnings surprises, even in cases where human attention constraints do not cause price inefficiencies. To examine this possibility, we conduct a quasi-placebo test using a subset of earnings announcements that have been found to have low investor attention but not suffer from inefficient price reactions as a result of low attention: post-close earnings announcements.

DeHaan et al. (2015) find that post-close earnings announcements are associated with lower investor attention, for example attracting fewer EDGAR downloads. But in work that looks specifically at price efficiency, Jiang et al. (2012) and Michaely et al. (2014) find that earnings announcements made after the market close have more efficient price reactions and a high degree of informational efficiency. ${ }^{22}$ Jiang et al. (2012) address this apparent contradiction, pointing out that although volume is lower and fewer investors may be paying attention to post-close earnings announcements, those trades that occur are more informed on average. Jiang et al. further suggest that firms may prefer to announce their earnings post-close in order to achieve a more efficient price reaction, with informed post-close trades conveying information to the general public. We thus see post-close announcements as a useful sample to test how HFT trading affects price efficiency when human attention is low but price efficiency is not low.

\footnotetext{
22 In recent work, Michaely, Rubin, and Vedrashko (2015) find that investors underreact to post-close announcements only when they occur on Fridays, and not when they occur on other days of the week. Only two of the post-close earnings announcements in our sample occur on Fridays.
} 
About 39\% of the earnings announcements in our sample are made after the market closes (i.e., between 4:00 pm and midnight). In Table 5 we replicate the analyses of short-term and longterm price efficiency from Equations (9) and (10), replacing the low-attention proxies with an indicator variable for post-close announcements.

\section{[Table 5 here]}

Looking first at the analysis of short-term price efficiency in the first column, we see that the coefficient estimate for Post-Close*HighUE is insignificant, indicating that there is no significant under-reaction to earnings surprises that are released post-close without HFTs. This is consistent with Jiang et al. (2012) and Michaely et al. (2014) and in contrast to the low-attention proxies analyzed in Section 4. Likewise, the participation of HFTs around post-close earnings announcements with earnings surprises does not significantly affect short-term price efficiency, as indicated by the insignificant coefficient estimate for three-way interaction term PostClose*HighUE*HFT. Taken together, these results show that HFTs do not always lead to significantly higher short-term price reactions. Rather, HFTs appear to enhance short-term price efficiency only when low attention would otherwise lead to under-reaction (Table 3).

The second column presents a similar picture for long-term price efficiency, with insignificant PEAD for post-close earnings surprises without HFTs (insignificant coefficient estimate on Post-Close*HighUE) and HFTs not significantly affecting PEAD when they trade on post-close earnings surprises (insignificant coefficient estimate on Post-Close*HighUE*HFT). Thus our conclusion remains intact, that HFTs enhance longer-term price efficiency when low attention would otherwise lead to higher PEAD (Table 4), but not when investor inattention has no discernable effect on PEAD (Table 5, second column).

\section{How does high-frequency trading improve price efficiency?}

So far our results suggest that HFT participation reduces the pricing inefficiencies around low-attention earnings announcements. A question that naturally follows is how the trading of HFTs reduces the price inefficiencies. One possibility is that HFTs account for a larger portion of trading when non-HFTs are distracted, in effect "filling in" for the distracted non-HFTs whose absence would otherwise lead to inefficient price reactions. Another possibility is that HFTs process the earnings news (by parsing textual news releases, for example) and aggressively trade on the information by demanding more liquidity than usual, and possibly supplying less (which 
may or may not lead to an increase in their overall trading percentage). Finally, it may be that HFT presence aids price efficiency primarily through a liquidity supply channel, as HFTs continue to supply liquidity at a time when non-HFTs may not, enabling liquidity-demanding non-HFTs to trade on the earnings news. To distinguish between these possibilities, in this section we first analyze the percentage of trading done by HFTs and then investigate whether the price efficiency gains documented earlier arise from abnormal HFT liquidity demand or supply.

\subsection{HFT share of trading volume}

It is not obvious a priori whether we should expect HFTs to account for the same fraction of trading on low-attention earnings announcements as on other announcement days. The general intuition of investor inattention is that when human decision-makers (non-HFTs) are inattentive, they trade less. If HFTs largely trade with each other, the withdrawal of non-HFTs could leave them accounting for a larger portion of trading volume on days when non-HFTs are distracted. On the other hand, the decline in non-HFT trading may lead to a commensurate decline in HFT trading if HFT strategies are mainly tied to non-HFT trading - for example, for HFTs that are primarily supplying liquidity to non-HFTs (as in a market-making strategy) or seeking to profit by picking off the limit orders of slower non-HFTs. In such cases we would expect no change in HFTs' percentage of trading. Table 6 compares mean and median trading percentages for HFTs on lowattention versus high-attention earnings announcements, measuring HFT total trading volume $\left(\mathrm{HFT}^{\mathrm{All}}\right)$, demand $\left(\mathrm{HFT}^{\mathrm{D}}\right)$, supply $\left(\mathrm{HFT}^{\mathrm{S}}\right)$, and trades in which HFTs demand liquidity while nonHFTs supply liquidity (HN) and those in which non-HFTs demand and HFTs supply liquidity $(\mathrm{NH})$. All measures are calculated based on trading from the time the earnings announcement is released until midnight the same day.

\section{[Table 6 here]}

The results in Table 6 are generally consistent across means and medians and across the five HFT measures within each panel, but the picture varies across the different attention proxies (different panels). When low-attention earnings announcements are defined by the aggregate proxy (Panel A), slow analyst speed (Panel C), Friday (Panel D), or high news distraction (Panel E), HFTs appear to account for a significantly higher fraction of trading. Meanwhile, Table 6 reveals no differences in HFT trading percentages for low-attention earnings announcements defined by low EDGAR downloads (Panel F) and low Google search volume (Panel G). 
On busy days (Panel B), HFTs account for a significantly lower portion of trading volume, perhaps because HFTs' strong inventory management concerns (Menkveld, 2013; SEC 2014) lead them to trade less in each stock when many stocks offer trading opportunities on the same day. We note that even though HFTs do a smaller proportion of trading on busy-day than on non-busy-day earnings announcements, their trading nonetheless leads to a more efficient response to earnings surprises (Tables 3 and 4). The fact that HFTs are associated with improved price efficiency on both busy days (when they trade proportionately less) and slow-analyst-speed announcements (when they trade proportionately more) suggests the need for a deeper examination of how they trade, which we explore in the following section.

\subsection{HFT demand versus supply in alleviating attention constraints}

To better understand how HFTs contribute to improved price efficiency following lowattention earnings announcements, we analyze HFT liquidity demand versus supply behavior. We focus on abnormal liquidity demand minus supply (rather than simple demand minus supply) because HFTs generally demand more liquidity than they supply (Table 1), and we are interested in how their behavior may differ on low-attention earnings announcements. In particular, we define a variable to capture HFT abnormal demand minus supply as follows: ${ }^{23}$

$\mathrm{HFT}_{i, t}{ }^{\mathrm{D}-\mathrm{S}}=1$ if HFT shares demanded minus supplied for stock $i$ on earnings announcement day $t$ is greater than the median for stock $i$ on non-earnings-announcement days; else 0.

We conduct price efficiency tests similar to those in equations (9) and (10), substituting the abnormal HFT demand-supply variable for the simple HFT variable used in the general analyses. We use the Aggregate low attention proxy in these tests. The coefficient estimate of interest in these regressions is the triple-interaction term LowAttn*HighUE*HFT ${ }^{D-S}$, which captures the incremental effect of HFT trading when HFT liquidity demand minus supply is high (compared to occasions when HFT liquidity demand minus supply is low). If the signs on the triple-interaction term are the same as in our main results (Tables 3 and 4), it would suggest that high HFT liquidity demand (relative to supply) drives the main results; opposite signs would suggest that high HFT liquidity supply is more responsible.

\section{[Table 7 here]}

\footnotetext{
${ }^{23}$ Constructing the demand minus supply variable using only the HFT/non-HFT interaction trades HN and NH, described in Section 3, yields identical inference.
} 
The results in Table 7 suggest that the price efficiency effects of HFT arise more from HFT liquidity demand rather than supply. The significantly positive coefficient estimate on the tripleinteraction term LowAttn*HighUE*HFT ${ }^{\mathrm{D}-S}$ in the first column (coefficient estimate of 0.053 with a $p$-value of 0.032) shows that when HFTs demand more liquidity relative to what they supply on low-attention earnings surprises, their activity more than offsets the general under-reaction to lowattention earnings surprises (coefficient estimate on LowAttn*HighUE of -0.035 with $p$-value of 0.079). A similar picture emerges for post-earnings-announcement drift in the second column: The generally positive drift for low attention earnings surprises (coefficient estimate on LowAttn*HighUE of 0.063 with a $p$-value of 0.019 ) is offset when HFTs demand more liquidity than they supply (coefficient estimate on LowAttn*HighUE*HFT ${ }^{D-S}$ of -0.064 with a $p$-value of 0.067). Thus it appears that HFTs improve price efficiency around low-attention earnings announcements primarily by demanding liquidity, consistent with HFTs processing and trading on textual news (as in Beschwitz et al., 2015), unencumbered by attention constraints.

\section{Robustness checks}

An important concern for our study is the correlation between HFT trading and firm size. Previous studies have documented that HFTs trade more in large stocks than in small stocks (e.g., Brogaard et al., 2014), and prior work on attention constraints has found that attention effects are lower in large stocks (Hirshleifer et al., 2009). Although we control for firm size in our price efficiency tests, it is possible that our results primarily reflect HFTs' preference for large stocks, which also have greater price efficiency, rather than the presence of HFTs reducing price inefficiencies. To address this concern, we divide our sample into small versus large firms (defined as below- and above-median market capitalization) and test each subsample separately using the aggregate attention proxy. ${ }^{24}$ Table 8 presents the results.

\section{[Table 8 here]}

Consider first Panel A, which presents the short-term price efficiency results (days $t$ to $t+1$ relative to the earnings announcement). The coefficient on LowAttn*HighUE, the classic attention effect, is significant for small firms (in the first column) but not for large firms (in the second column), consistent with Hirshleifer et al.’s (2009) finding that attention effects are stronger for

\footnotetext{
${ }^{24}$ The number of observations differs in the small firm and large firm subsamples because of data availability for the regression control variables and individual proxies used to calculate the aggregate proxy.
} 
smaller firms. Notably, the marginal effect of HFTs, captured by the triple-interaction term LowAttn*HighUE*HFT, is significant for small firms, suggesting that our results are not driven by large firms alone.

In Panel B we repeat the small firm/large firm subsample analyses for post-earningsannouncement drift (days $t+2$ to $t+45$ after the earnings announcement). We find that PEAD is higher for stocks with low attention on earnings surprises only among the small firms (significant positive coefficient on LowAttn*HighUE for small firms in first column, not for large firms in second column) and that the marginal impact of HFTs reverses the PEAD among small firms. Thus the subsample analyses in both panels indicate that the HFT effect we document in the main study is not merely driven by HFTs trading in large stocks.

Previous studies of the effects of investor limited attention on price efficiency have examined cumulative abnormal returns over various time periods, so we also test the robustness of our results over different time windows. Table 9 replicates the analysis of short-term price reactions to earnings surprises (in Table 3) over one-day (Panel A) and three-day (Panel B) periods.

\section{[Table 9 here]}

The results for the aggregate attention proxy, in the first column, provide support for our hypothesis in both one-day (Panel A) and three-day (Panel B) cumulative abnormal returns. The coefficient estimates for the triple interaction term LowAttn*HighUE*HFT are positive (0.047 and 0.183 ) and significant ( $p$-values of 0.026 and $<.001$, respectively), indicating that earnings announcements identified as low-attention by the aggregate metric have greater short-term stock price response to earnings surprises when they have HFT trading. At the one-day horizon, the coefficient estimates on the three-way interaction term are significant for the busy day, slow analyst speed, and high news distraction attention proxies (Panel A), while the low EDGAR proxy becomes significant and high news distraction loses significance at the three-day horizon (Panel B). The Google proxy continues to show no significant results, as in Table 3. Overall, Table 9 shows that our results for short-term price efficiency are robust to different short-term horizons.

Table 10 replicates the analysis of long-term price reactions to earnings surprises (PEAD) (in Table 4) over a 30-day horizon.

\section{[Table 10 here]}

The results for the aggregate attention proxy, in the first column, provide support for our hypothesis. The coefficient estimate for the triple interaction term LowAttn*HighUE*HFT is 
negative (-0.148) and significant ( $p$-value of 0.002), indicating that earnings announcements identified as low-attention by the aggregate metric have lower 30-day PEAD when they have HFT trading. The individual low-attention proxies based on busy days, slow analyst speed, high news distraction, and low EDGAR all show significant effects of HFT activity on low-attention announcements with earnings surprises, echoing the findings of Table 4 over the 45-day horizon.

Finally, we examine the robustness of our results to alternative definitions of HFT trading. In Panel A of Table 11, we define the HFT indicator variable as having the value one if HFTs represent at least five percent of trading volume following the earnings announcement (instead of any positive volume in our main analyses), else zero. In Panel B, we define the HFT indicator variable as having the value one if HFTs trade in the two hours following the earnings announcement (instead of the entire remaining trading day in our main analysis), else zero. Low attention is measured using the Aggregate proxy. The results in both panels are consistent with our main results.

\section{[Table 11 here]}

\section{Conclusion}

In this study we examine the changing role of attention in modern financial markets. A large portion of trading in today's markets is executed by machines that trade at millisecond and microsecond speeds using pre-programmed algorithms with little to no human intervention. The preponderance of these super-fast computers, known as high-frequency traders (HFTs), raises questions about the effects of attention constraints on price efficiency. Previous research has shown that the attention constraints of human traders (both investors and market makers) lead to systematic effects on stock prices. A number of papers have shown that when a firm announces its earnings at times of low attention, investors generally trade less in those stocks, as a result of which price responses are inefficient.

Given that machines are not expected to suffer from limited attention or distraction, does this new type of traders - the HFTs - improve price efficiency during times of low (human) attention? Using a large set of proxies for investor attention, we answer this question. Our study is made possible by a dataset made available to us by NASDAQ OMX that identifies trader types as high-frequency and non-high-frequency, a feature not available in standard public datasets. 
We employ six attention proxies and an aggregate measure to examine the participation of HFTs around low-attention earnings announcements. We find that HFT trading tempers the previously documented effects of low attention on stock price efficiency. We test both short- and long-term price efficiency and find that high-frequency trading on low-attention announcements is associated with greater stock price responsiveness to earnings surprises and reduced long-term price drift, specifically when human attention constraints cause inefficient reactions to earnings surprises. Our findings are stronger for small stocks, where investor distraction more often leads to price inefficiencies. While HFTs are active as both liquidity demanders and liquidity suppliers on low-attention announcements, we find that that price efficiency improves more when HFTs are more heavily demanding liquidity. We thus conclude that it is HFTs' ability to process and trade on news without human distraction that most improves price efficiency. Our results are important in that they highlight the changing role of attention in modern financial markets and reveal a previously undocumented positive role played by HFTs.

\section{REFERENCES}

Aboody, David, Reuven Lehavy, and Brett Trueman, 2010, Limited attention and the earnings announcement returns of past stock market winners, Review of Accounting Studies 15: 317344.

Balakrishnan, Karthik, Eli Bartov, and Lucile Faurel, 2010, Post profit/loss announcement drift, Journal of Accounting and Economics 50: 20-41.

Bali, Turan, Lin Peng, Yannan Shen, and Yi Tang, 2014, Liquidity shocks and stock market reactions, Review of Financial Studies 27: 1434-1485.

Barber, Brad, and Terrence Odean, 2008, All that glitters: The effect of attention and news on the buying behavior of individual and institutional investors, Review of Financial Studies 21: 785-818.

Beschwitz, Bastian von, Donald B. Keim, and Massimo Massa, 2015, First to "read” the news: news analytics and institutional trading, Working paper.

Biais, Bruno, Thierry Foucault, and Sophie Moinas, 2015, Equilibrium fast trading, Journal of Financial Economics 116: 292-313.

Biais, Bruno, and Paul Woolley, 2011, High-frequency trading. Working paper, IDEI.

BIS, 2011, Foresight project on the future of computer trading in financial markets http://www.bis.gov.uk/foresight. 
Bradley, Daniel, Jonathan Clarke, Suzanne Lee, and Chayawat Ornthanalai, 2014, Are analysts' recommendations informative? Intraday evidence on the impact of time stamp delays, Journal of Finance 69: 645-673.

Brogaard, Jonathan, 2010, High frequency trading and price volatility, Working paper.

Brogaard, Jonathan, Terrence Hendershott, and Ryan Riordan, 2014, High frequency trading and price discovery, Review of Financial Studies 27: 2267-2306.

Brown, Stephen, Stephen A. Hillegeist, and Kin Lo, 2009, The effect of earnings surprises on information asymmetry, Journal of Accounting and Economics 47: 208-225.

Carrion, Allen, 2013, Very fast money: High-frequency trading on the NASDAQ, Journal of Financial Markets 16: 680-711.

Chaboud, Alain, Benjamin Chiquoine, Erik Hjalmarsson, and Clara Vega, 2014, Rise of the machines: Algorithmic trading in the foreign exchange market, Journal of Finance 69: 20452084.

Chakrabarty, Bidisha, and Pamela C. Moulton, 2012, Earnings announcements and attention constraints: The role of market design, Journal of Accounting and Economics 53: 612-634.

Chordia, Tarun, Avanidhar Subrahmanyam, and Qing Tong, 2014, Have capital market anomalies attenuated in the recent era of high liquidity and trading activity? Journal of Accounting and Economics 58: 41-58.

Corwin, Shane, and Jay Coughenour, 2008, Limited attention and the allocation of effort in securities trading, Journal of Finance 63: 3031-3067.

Da, Zhi, Joey Engelberg, and Pengjie Gao, 2011, In search of attention, Journal of Finance 66: 1461-1499.

Damodaran, Aswath, 1989, The weekend effect in information releases: A study of earnings and dividend announcements, Review of Financial Studies 2: 607-623.

DeHaan, Ed, Terry Shevlin, and Jacob Thornock, 2015, Market (in)attention and the strategic scheduling and timing of earnings announcements, Journal of Accounting and Economics 60: 36-55.

DellaVigna, Stefano, and Joshua Pollet, 2009, Investor inattention and Friday earnings announcements, Journal of Finance 64: 709-749.

Drake, Michael, Darren Roulstone, and Jacob Thornock, 2012, Investor information demand: Evidence from Google searches around earnings announcements, Journal of Accounting Research 50: 1001-1040.

Drake, Michael, Darren Roulstone, and Jacob Thornock, 2014, The determinants and consequences of information acquisition via EDGAR, Contemporary Accounting Research, forthcoming.

Engelberg, Joseph, R. David McLean, and Jeffrey Pontiff, 2015, Anomalies and news, Working paper.

Gabaix, Xavier, David Laibson, Guillermo Moloche, and Stephen Weinberg, 2006, Costly information acquisition: Experimental analysis of a boundedly rational model, American Economic Review 96: 1043-1068. 
Graham, John, and Alok Kumar, 2006, Do dividend clienteles exist? Evidence on dividend preferences of retail investors, Journal of Finance 61: 1305-1336.

Green, John, Jeremiah Hand, and Mark Soliman, 2011, Going, going, gone? The apparent demise of the accruals anomaly, Management Science 57: 797-816.

Gross-Klussmann, Axel, and Nikolaus Hautsch, 2011, When machines read the news: using automated text analytics to quantify high frequency news-implied market reactions, Journal of Empirical Finance 18, 324-340.

Hasbrouck, Joel, and Gideon Saar, 2013, Low-latency trading, Journal of Financial Markets 16: 646-679.

Hendershott, Terrence, Charles Jones, and Albert Menkveld, 2011, Does algorithmic trading improve liquidity? Journal of Finance 66: 1-33.

Hirshleifer, David, Sonya Lim, and Siew Hong Teoh, 2009, Driven to distraction: Extraneous events and underreaction to earnings news, Journal of Finance 64: 2289-2325.

Hong, Harrison, and Jeremy C. Stein, 1999, A unified theory of underreaction, momentum trading, and overreaction in asset markets, Journal of Finance 54: 2143-2184.

Hope, Bradley, 2015, How computers trawl a sea of data for stock picks, Wall Street Journal April 1. http://www.wsj.com/articles/how-computers-trawl-a-sea-of-data-for-stock-picks1427941801.

Huberman, Gur, and Tomer Regev, 2001, Contagious speculation and a cure for cancer: A nonevent that made stock prices soar, Journal of Finance 56: 387-396

Jain, Pankaj, 2005, Financial market design and the equity premium: Electronic vs. floor trading, Journal of Finance 60: 2955-2985.

Jiang, Christine, Tanakorn Likitapiwat, and Thomas McInish, 2012, Information content of earnings announcements: Evidence from after-hours trading, Journal of Financial and Quantitative Analysis 47: 1303-1330.

Kahneman, Daniel, 1973, Attention and Effort (Prentice-Hall, Englewood Cliffs, NJ).

Kirilenko, Andrei, Albert S. Kyle, Mehrdad Samadi, and Tugkan Tuzun, 2014, The flash crash: The impact of high-frequency trading on an electronic market, Working paper, CFTC.

Kothari, S.P., 2001, Capital markets research in accounting, Journal of Accounting and Economics 31: 105-231.

Lee, Charles, 1992, Earnings news and small traders: An intraday analysis, Journal of Accounting and Economics 15: 265-302.

Madsen, Joshua, and Marina Niessner. 2014. Is investor attention for sale? The role of advertising in financial markets, Working Paper.

Mashruwala, Christina, Shivaram Rajgopal, and Terry Shevlin, 2006, Why is the accrual anomaly not arbitraged away? The role of idiosyncratic risk and transaction costs, Journal of Accounting and Economics 42: 3-33.

McLean, David, and Jeffrey Pontiff, 2015, Does academic research destroy stock return predictability? Journal of Finance, forthcoming. 
Menkveld, Albert, 2013, High frequency trading and the new market makers, Journal of Financial Markets 16: 712-740.

Michaely, Roni, Amir Rubin, and Alexander Vedrashko, 2014, Corporate governance and the timing of earnings announcements, Review of Finance 18:2003-2044.

Michaely, Roni, Amir Rubin, and Alexander Vedrashko, 2015, When is the best time to hide earnings news? Working paper.

Miller, Gregory S., 2002, Earnings performance and discretionary disclosure, Journal of Accounting Research 40: 173-204.

Patell, James, and Mark Wolfson, 1982, Good news, bad news, and the intraday timing of corporate disclosures, Accounting Review 57: 509-527.

Peng, Lin, 2005, Learning with information capacity constraints, Journal of Financial and Quantitative Analysis 40: 307-329.

Seasholes, Mark, and Guojun Wu, 2007, Predictable behavior, profits, and attention, Journal of Empirical Finance 14: 590-610.

Securities and Exchange Commission, 2010, Concept release on equity market structure http://www.sec.gov/rules/concept/2010/34-61358.pdf

Securities and Exchange Commission, 2014, Equity market structure literature review Part II: High frequency trading. http://www.sec.gov/marketstructure/research/hft_lit_review_march_2014.pdf

Sussman, Adam, 2012, US equities: State of the Industry 2012. Link to the report is available at: http://www.tabbgroup.com/PublicationDetail.aspx?PublicationID=1047\&MenuID=44\&Pare ntMenuID=2\&PageID=43. 


\section{Appendix A: Variable sources and definitions}

\begin{tabular}{|c|c|c|}
\hline Variable & Data source & Definition \\
\hline \multicolumn{3}{|l|}{ HFT Trading Variables } \\
\hline $\mathrm{HFT}^{\text {All }}$ & NASDAQ OMX & $(2 * \mathrm{HH}+\mathrm{HN}+\mathrm{NH}) /(2 *$ Total Volume $)$ \\
\hline $\mathrm{HFT}^{\mathrm{D}}$ & NASDAQ OMX & $(\mathrm{HH}+\mathrm{HN}) /$ Total Volume \\
\hline $\mathrm{HFT}^{\mathrm{S}}$ & NASDAQ OMX & $(\mathrm{HH}+\mathrm{NH}) /$ Total Volume \\
\hline HN\% & NASDAQ OMX & HN / Total Volume \\
\hline NH\% & NASDAQ OMX & NH / Total Volume \\
\hline \multicolumn{3}{|l|}{ Attention Proxies } \\
\hline Friday earnings announcements & $\begin{array}{l}\text { IBES, Compustat, Wall } \\
\text { Street Horizon, Factiva }\end{array}$ & $\begin{array}{l}\text { Derived from IBES variable ANNDAT and Compustat, Wall Street } \\
\text { Horizon, and Factiva cross-check }\end{array}$ \\
\hline Post-close & $\begin{array}{l}\text { IBES, Compustat, Wall } \\
\text { Street Horizon, Factiva }\end{array}$ & $\begin{array}{l}\text { Derived from IBES variable ANNTIM and Compustat, Wall Street } \\
\text { Horizon, and Factiva cross-check }\end{array}$ \\
\hline Busy day & Compustat & Multiple announcements on the same day \\
\hline Analyst Speed & IBES & $-1 \times \ln \left(\frac{1}{j} \sum_{j=1}\left[1+\right.\right.$ Weekdays until forecast update $\left.\left.e_{j}\right]\right)$ \\
\hline EDGAR downloads & $\begin{array}{l}\text { SEC, via authors of Drake, } \\
\text { Roulstone, and Thornock } \\
\text { (2014) }\end{array}$ & $\ln \left(E D G A R_{t}\right)-\ln \left(\frac{1}{5} \sum_{w=1}^{5} E D G A R_{w}\right)$ \\
\hline Google Search Volume Index (SVI) & $\begin{array}{l}\text { http://www.google.com/tren } \\
\text { ds/ }\end{array}$ & $\begin{array}{l}\ln (1+\mathrm{SVI}) \text {, where } \mathrm{SVI}=\mathrm{SVI}_{\mathrm{d}} * \mathrm{SVI}_{\mathrm{w}} / 100 \text {, and } \mathrm{SVI}_{\mathrm{d}}=\text { daily SVI, } \\
\mathrm{SVI}_{\mathrm{w}}=\text { weekly SVI }\end{array}$ \\
\hline News distraction & Factiva & $\begin{array}{l}\text { Count of (Dow Jones NewsWire stories for firm } i \text { on day } t \text { ) - Count } \\
\text { of (Dow Jones NewsWire stories about earnings for firm } i \text { on day } t \text { ) }\end{array}$ \\
\hline \multicolumn{3}{|l|}{ Control Variables } \\
\hline Market capitalization & COMPUSTAT & Price*Shares Outstanding \\
\hline Market-to-book ratio & COMPUSTAT & Market Capitalization/Book Value of Equity \\
\hline Price & CRSP & Share price \\
\hline Spread & CRSP & Closing Ask Quote minus Closing Bid Quote \\
\hline Dollar Volume & CRSP & Price*Volume \\
\hline VIX & $\begin{array}{l}\text { http://www.cboe.com/micro } \\
\text { /vix/historical.aspx }\end{array}$ & Volitility index from Chicago Board Options Exchange \\
\hline Cumulative abnormal return (CAR) & CRSP & $\begin{array}{l}{\left[\left(\mathrm{P}_{\mathrm{t}}-\mathrm{P}_{\mathrm{s}}\right) / \mathrm{P}_{\mathrm{s}}\right]-\mathrm{CRSP} \text { Value weighted market index over same period }} \\
\text { beginning at } \mathrm{s} \text { and ending at } \mathrm{t}\end{array}$ \\
\hline Unexpected earnings (UE) & CRSP, IBES & $\begin{array}{l}\text { (Earnings - Analyst consensus forecast)/Price, with price measured } \\
\text { as of the end of the quarter in which the earnings are announced }\end{array}$ \\
\hline
\end{tabular}




\section{Appendix B: Illustration of HFT calculations}

NASDAQ trader-type classifications: HH = HFT demanding and HFT supplying liquidity; HN = HFT demanding and non-HFT supplying liquidity; $\mathrm{NH}=$ non-HFT demanding and HFT supplying liquidity; NN = non-HFT demanding and non-HFT supplying liquidity.

Consider the following set of trades in one stock on one day:

\begin{tabular}{|c|c|c|c|}
\hline Trade \# & NASDAQ Trader-Type Classification & Shares traded & $\begin{array}{r}\text { HFT shares } \\
\text { demanded + HFT } \\
\text { shares supplied }\end{array}$ \\
\hline & $\mathrm{HH}$ & 100 & 200 \\
\hline & $\mathrm{HN}$ & 200 & 200 \\
\hline & $\mathrm{NH}$ & 300 & 300 \\
\hline & $\mathrm{NN}$ & 400 & 0 \\
\hline & Totals $=$ & 1000 & 700 \\
\hline & Total shares demanded + shares supplied $=2 \times$ trading volume $=$ & 2000 & \\
\hline Variable & Calculation & & Value \\
\hline HFT $^{\text {All }}$ & HFT $\%=$ (shares demanded by HFT + shares supplied by HFT $) /(2 x$ tr & rolume): & $35 \%$ \\
\hline $\mathrm{HFT}^{\mathrm{D}}$ & HFT Demand \% = (shares with HFT demanding liquidity)/(trading vol & & $30 \%$ \\
\hline $\mathrm{HFT}^{\mathrm{S}}$ & HFT Supply \% = (shares with HFT supplying liquidity)/(trading volum & & $40 \%$ \\
\hline HN\% & HFT Demand with non-HFT Supply \% $=($ HN shares traded $) /($ trading & & $20 \%$ \\
\hline NH\% & non-HFT Demand with HFT Supply $\%=($ NH shares traded $) /($ trading $~$ & & $30 \%$ \\
\hline
\end{tabular}




\section{Table 1: Sample descriptive statistics}

This table presents descriptive statistics for the sample of 103 NASDAQ stocks over all trading days in 2008 and 2009. In Panel A, means are calculated by stock, and cross-sectional statistics are reported in the table. Market capitalization and Book-to-market ratio are calculated from quarter-end values; Price is the average daily closing price of the stock; Trading volume is the average daily NASDAQ trading volume; and \# Earnings announcements is the number of earnings announcements per stock in the sample period.

Panel B presents descriptive statistics for HFT trading, with means calculated by stock and cross-sectional statistics reported in the table. $H F T^{\text {All }}$ measures the percentage of trading volume executed by HFTs; $H F T^{D}$ measures the percentage of trading volume in which HFTs demand liquidity; $H F T^{S}$ measures the percentage of trading volume in which HFTs supply liquidity; HN\% measures the percentage of trading volume in which HFTs demand and non-HFTs supply liquidity; and $\mathrm{NH} \%$ measures the percentage of trading volume in which non-HFTs demand and HFTs supply liquidity.

In Panel C, the first two lines report the breakdown of all earnings announcements, beginning with the total number of earnings announcements in the sample (Total), and then separating out earnings announcements that are made on Fridays (Friday). The remaining rows in Panel C present cross-sectional statistics across all earnings announcements for the number of other earnings announcements made on the same day (\# Other earnings announcements ); the speed with which analysts revise their earnings forecasts (Days until analyst update and Analyst speed ); the number of nonearnings news (News distraction counts); the number of financial form downloads from the SEC's EDGAR database (EDGAR downloads and the EDGAR variable); and Google search SVI variable, measured as the log of one plus the Google Search Volume Index scaled for the two-year sample period.

\begin{tabular}{lccc}
\hline Panel A: Sample stocks & Mean & Median & Std Dev \\
\hline & 19.60 & 1.83 & 39.80 \\
Market capitalization (\$ billion) & 3.35 & 2.44 & 3.57 \\
Market-to-book ratio & 36.47 & 22.32 & 50.72 \\
Price & 2.03 & 0.36 & 4.21 \\
Trading volume (shares million) & 7.98 & 8.00 & 0.14 \\
\# Earnings announcements & &
\end{tabular}

\begin{tabular}{lcccc}
\hline Panel B: Trading volume percentages & & & \\
\hline & $\underline{\text { Mean }}$ & $\underline{\text { Median }}$ & $\underline{\underline{S t d} \text { Dev }}$ \\
HFT $^{\text {All }}$ & 28.8 & 27.0 & 11.8 \\
$\mathrm{HFT}^{\mathrm{D}}$ & 32.8 & 34.5 & 11.4 \\
$\mathrm{HFT}^{\mathrm{S}}$ & 24.7 & 17.1 & 15.3 \\
$\mathrm{HN} \%$ & 24.9 & 25.1 & 8.2 \\
$\mathrm{NH} \%$ & 16.8 & 12.7 & 9.7 \\
\hline
\end{tabular}




\begin{tabular}{lccc}
\hline \multicolumn{4}{l}{ Panel C: Earnings announcements and attention indicators } \\
\hline & $\underline{\text { Total }}$ & $\underline{\text { Fridays }}$ & \\
\# Earnings announcements & 745 & 60 & \\
\% Earnings announcements & $100 \%$ & $8 \%$ & \\
& $\underline{\text { Mean }}$ & $\underline{\text { Median }}$ & Std Dev \\
Multiple earnings announcements & 233 & 202 & 152 \\
Days until analyst update (untransformed) & 3.0 & 1.3 & 4.4 \\
Analyst speed variable & -1.04 & -0.81 & 0.74 \\
News distraction counts & 1.95 & 0.00 & 3.68 \\
EDGAR downloads (untransformed) & 137 & 75 & 175 \\
EDGAR variable & 0.68 & 0.69 & 0.61 \\
Google search SVI variable & 3.61 & 3.78 & 0.77 \\
\hline
\end{tabular}




\section{Table 2: Correlation table for low-attention proxies}

This table presents Pearson correlation coefficients between earnings announcements designated as low-attention under the six attention proxies: Busy Day signals announcements with an above-median number of announcements released on the same day; Slow Analyst Speed signals announcements with below-median analyst speed; High News Distraction signals announcements with above-median non-earnings-related news; Friday signals announcements made on Fridays; Low EDGAR signals announcements that experience below-median abnormal download volume from the SEC's EDGAR database; Low Google Search signals announcements that experience below-median Google search volume. P-values are reported in parentheses below the correlation estimates.

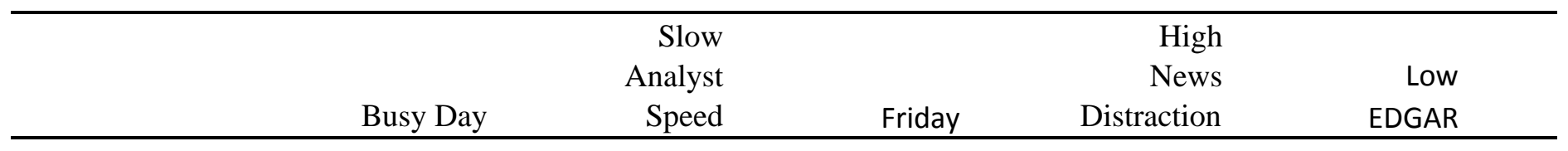

\section{Slow Analyst Speed}

$$
-0.022
$$

Friday

$\begin{array}{lr}-0.205 * * * & 0.012 \\ (<0.001) & (0.765)\end{array}$

High News Distraction

$-0.160 * * * \quad 0.054$

\subsection{4}

(0.178)

Low EDGAR

Low Google Search
0.041

(0.277)
$-0.034$

0.079

(0.473)

\subsection{5}

(0.502)

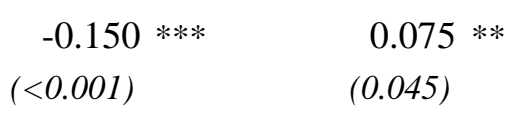

0.078

$-0.007$

$-0.010$

(0.104)
(0.842) 


\section{Table 3: HFT and Short-term price efficiency}

This table presents multivariate tests of price efficiency with versus without HFT. The dependent variable is the cumulative abnormal return for stock $i$ on earnings announcement days $t$ and $t+1$; cumulative abnormal return is expressed in decimal form, so 0.01 equals $1 \%$. Low Attention is equal to one if the earnings announcement falls into the low-attention category given the proxy being used, else zero; Aggregate reflects the combined distribution of Friday, Busy Day, Slow Analyst Speed, High News Distraction, and Low EDGAR earnings announcements. HFT is equal to one if there is high-frequency trading in the rest of the day following the earnings announcement, else zero; HighUE is equal to one if the announcement has above-median unexpected earnings, else zero. Regressions also include as controls market capitalization and earnings surprise volatility over the prior four years and month and year indicators. All controls are also interacted with HighUE; the intercept, controls, and interacted controls are not reported. P-values (reported in parentheses below coefficient estimates) are based on standard errors that are clustered by announcement day. ${ }^{*}, * *$, and ${ }^{* * *}$ denote significance at the $10 \%, 5 \%$, and $1 \%$ levels.

\begin{tabular}{|c|c|c|c|c|c|c|}
\hline Low Attention proxy & Aggregate & Busy Day & $\begin{array}{l}\text { Slow Analyst } \\
\text { Speed }\end{array}$ & $\begin{array}{l}\text { High News } \\
\text { Distraction } \\
\end{array}$ & Low EDGAR & $\begin{array}{c}\text { Low Google } \\
\text { Search }\end{array}$ \\
\hline Low Attention & $\begin{array}{l}0.100 * * * \\
(<.001)\end{array}$ & $\begin{array}{r}0.042 \\
(0.116)\end{array}$ & $\begin{array}{r}0.040 \\
(0.139)\end{array}$ & $\begin{array}{r}0.012 \\
(0.698)\end{array}$ & $\begin{array}{c}0.043 \text { * } \\
(0.095)\end{array}$ & $\begin{array}{c}0.068 \text { * } \\
(0.096)\end{array}$ \\
\hline HighUE & $\begin{array}{r}0.015 \\
(0.736)\end{array}$ & $\begin{array}{l}-0.015 \\
(0.762)\end{array}$ & $\begin{array}{r}0.005 \\
(0.916)\end{array}$ & $\begin{array}{l}-0.064 \\
(0.152)\end{array}$ & $\begin{array}{r}0.010 \\
(0.860)\end{array}$ & $\begin{array}{r}0.027 \\
(0.726)\end{array}$ \\
\hline HFT & $\begin{array}{r}0.028 \\
(0.144)\end{array}$ & $\begin{array}{r}0.005 \\
(0.790)\end{array}$ & $\begin{array}{r}0.021 \\
(0.232)\end{array}$ & $\begin{array}{r}0.002 \\
(0.884)\end{array}$ & $\begin{array}{r}0.019 \\
(0.360)\end{array}$ & $\begin{array}{r}0.017 \\
(0.660)\end{array}$ \\
\hline Low Attention * HighUE & $\begin{array}{l}-0.165 * * * \\
(<.001)\end{array}$ & $\begin{array}{l}-0.095 * * \\
(0.024)\end{array}$ & $\begin{array}{l}-0.089 * * \\
(0.039)\end{array}$ & $\begin{array}{l}-0.030 \\
(0.589)\end{array}$ & $\begin{array}{l}-0.085 * * \\
(0.047)\end{array}$ & $\begin{array}{l}-0.042 \\
(0.507)\end{array}$ \\
\hline Low Attention * HFT & $\begin{array}{l}-0.094 * * * \\
(0.002)\end{array}$ & $\begin{array}{l}-0.016 \\
(0.555)\end{array}$ & $\begin{array}{l}-0.050 * \\
(0.091)\end{array}$ & $\begin{array}{l}-0.027 \\
(0.398)\end{array}$ & $\begin{array}{l}-0.032 \\
(0.227)\end{array}$ & $\begin{array}{l}-0.075 * \\
(0.081)\end{array}$ \\
\hline HFT $*$ HighUE & $\begin{array}{l}-0.037 \\
(0.205)\end{array}$ & $\begin{array}{l}-0.028 \\
(0.395)\end{array}$ & $\begin{array}{l}-0.029 \\
(0.296)\end{array}$ & $\begin{array}{l}-0.005 \\
(0.827)\end{array}$ & $\begin{array}{l}-0.046 \\
(0.229)\end{array}$ & $\begin{array}{r}0.009 \\
(0.874)\end{array}$ \\
\hline Low Attention * HighUE * HFT & $\begin{array}{l}0.173 * * * \\
(<.001)\end{array}$ & $\begin{array}{l}0.066 * \\
(0.058)\end{array}$ & $\begin{array}{l}0.097 \text { ** } \\
(0.020)\end{array}$ & $\begin{array}{r}0.057 \\
(0.166)\end{array}$ & $\begin{array}{l}0.088 * * \\
(0.026)\end{array}$ & $\begin{array}{r}0.046 \\
(0.241)\end{array}$ \\
\hline Controls (Interacted) & yes & yes & yes & yes & yes & yes \\
\hline \# Observations & 576 & 679 & 603 & 679 & 642 & 398 \\
\hline
\end{tabular}




\section{Table 4: HFT and Long-term price efficiency}

This table presents multivariate tests of price efficiency with versus without HFT. The dependent variable is the cumulative abnormal return for stock $i$ from 2 days after earnings announcement day $t$ to 45 days after; cumulative abnormal return is expressed in decimal form, so 0.01 equals $1 \%$. Low Attention is equal to one if the earnings announcement falls into the low-attention category given the proxy being used, else zero; Aggregate reflects the combined distribution of Friday, Busy Day, Slow Analyst Speed, High News Distraction, and Low EDGAR earnings announcements. HFT is equal to one if there is high-frequency trading in the rest of the day following the earnings announcement, else zero; HighUE is equal to one if the announcement has above-median unexpected earnings, else zero. Regressions also include as controls market capitalization and earnings surprise volatility over the prior four years and month and year indicators. All controls are also interacted with HighUE; the intercept, controls, and interacted controls are not reported. P-values (reported below coefficient estimates) are based on standard errors that are clustered by announcement day. ${ }^{*}, * *$, and $* * *$ denote significance at the $10 \%, 5 \%$, and $1 \%$ levels.

\begin{tabular}{|c|c|c|c|c|c|c|}
\hline \multicolumn{7}{|c|}{ Dependent variable $=$ Cumulative abnormal return (CAR) on post-earnings-announcement days $t+2$ to $t+45$} \\
\hline Low Attention proxy & Aggregate & Busy Day & $\begin{array}{l}\text { Slow Analyst } \\
\text { Speed }\end{array}$ & $\begin{array}{l}\text { High News } \\
\text { Distraction }\end{array}$ & Low EDGAR & $\begin{array}{c}\text { Low Google } \\
\text { Search }\end{array}$ \\
\hline Low Attention & $\begin{array}{l}-0.044 \\
(0.230)\end{array}$ & $\begin{array}{l}-0.083 \text { ** } \\
(0.020)\end{array}$ & $\begin{array}{l}-0.006 \\
(0.879)\end{array}$ & $\begin{array}{r}-0.04 \\
(0.492)\end{array}$ & $\begin{array}{l}-0.010 \\
(0.796)\end{array}$ & $\begin{array}{r}0.055 \\
(0.352)\end{array}$ \\
\hline HighUE & $\begin{array}{c}-0.002 \\
(0.983)\end{array}$ & $\begin{array}{l}-0.025 \\
(0.814)\end{array}$ & $\begin{array}{r}0.012 \\
(0.893)\end{array}$ & $\begin{array}{r}0.01 \\
(0.919)\end{array}$ & $\begin{array}{l}-0.075 \\
(0.465)\end{array}$ & $\begin{array}{r}0.027 \\
(0.802)\end{array}$ \\
\hline HFT & $\begin{array}{r}0.009 \\
(0.715)\end{array}$ & $\begin{array}{l}-0.054 * * \\
(0.046)\end{array}$ & $\begin{array}{r}0.019 \\
(0.443)\end{array}$ & $\begin{array}{l}-0.013 \\
(0.556)\end{array}$ & $\begin{array}{l}-0.007 \\
(0.846)\end{array}$ & $\begin{array}{r}0.065 \\
(0.169)\end{array}$ \\
\hline Low Attention * HighUE & $\begin{array}{l}0.220 * * * \\
(<.001)\end{array}$ & $\begin{array}{l}0.137 \text { ** } \\
(0.025)\end{array}$ & $\begin{array}{l}0.155^{* *} \\
(0.015)\end{array}$ & $\begin{array}{c}0.135 * \\
(0.065)\end{array}$ & $\begin{array}{l}0.139 * * \\
(0.038)\end{array}$ & $\begin{array}{r}0.027 \\
(0.776)\end{array}$ \\
\hline Low Attention * HFT & $\begin{array}{r}0.030 \\
(0.442)\end{array}$ & $\begin{array}{l}0.084 * * \\
(0.025)\end{array}$ & $\begin{array}{r}0.003 \\
(0.943)\end{array}$ & $\begin{array}{r}0.032 \\
(0.589)\end{array}$ & $\begin{array}{r}0.005 \\
(0.903)\end{array}$ & $\begin{array}{l}-0.104 * \\
(0.084)\end{array}$ \\
\hline HFT * HighUE & $\begin{array}{r}0.042 \\
(0.326)\end{array}$ & $\begin{array}{r}0.079 \\
(0.109)\end{array}$ & $\begin{array}{r}0.064 \\
(0.200)\end{array}$ & $\begin{array}{r}0.023 \\
(0.568)\end{array}$ & $\begin{array}{r}0.081 \\
(0.191)\end{array}$ & $\begin{array}{l}-0.024 \\
(0.761)\end{array}$ \\
\hline Low Attention * HighUE * HFT & $\begin{array}{l}-0.208 * * * \\
(<.001)\end{array}$ & $\begin{array}{l}-0.138 * * \\
(0.018)\end{array}$ & $\begin{array}{l}-0.173 * * * \\
(0.005)\end{array}$ & $\begin{array}{l}-0.107 * \\
(0.071)\end{array}$ & $\begin{array}{l}-0.120 * \\
(0.050)\end{array}$ & $\begin{array}{r}0.013 \\
(0.446)\end{array}$ \\
\hline Controls (Interacted) & yes & yes & yes & yes & yes & yes \\
\hline \# Observations & 576 & 679 & 603 & 679 & 642 & 398 \\
\hline
\end{tabular}




\section{Table 5: Post-close placebo tests}

This table presents multivariate tests of price efficiency with versus without HFT. The dependent variable is the cumulative abnormal return (CAR) for stock $i$ on earnings announcement days $t$ and $t+1$ in the first column and day $t+2$ to $t+45$ in the second column; cumulative abnormal return is expressed in decimal form, so 0.01 equals $1 \%$. Post-Close is equal to one if the earnings announcement occurs between 4:00 p.m. and midnight, else zero. HFT is equal to one if there is high-frequency trading in the rest of the day following the earnings announcement, else zero; HighUE is equal to one if the announcement has above-median unexpected earnings, else zero. Regressions also include as controls market capitalization and earnings surprise volatility over the prior four years and month and year indicators. All controls are also interacted with HighUE; the intercept, controls, and interacted controls are not reported. P-values (reported in parentheses below coefficient estimates) are based on standard errors that are clustered by announcement day. ${ }^{*}, *$, and $* * *$ denote significance at the $10 \%, 5 \%$, and $1 \%$ levels.

\begin{tabular}{|c|c|c|}
\hline Dependent variable & $\begin{array}{c}\text { CAR on } \\
\text { earnings announcement } \\
\text { days } t \text { to } t+1 \\
\end{array}$ & $\begin{array}{c}\text { CAR on } \\
\text { earnings announcement } \\
\text { days } t+2 \text { to } t+45 \\
\end{array}$ \\
\hline Post-Close & $\begin{array}{r}0.025 \\
(0.290)\end{array}$ & $\begin{array}{r}0.038 \\
(0.351)\end{array}$ \\
\hline HighUE & $\begin{array}{l}-0.002 \\
(0.969)\end{array}$ & $\begin{array}{r}0.191 \\
(0.189)\end{array}$ \\
\hline HFT & $\begin{array}{r}0.016 \\
(0.472)\end{array}$ & $\begin{array}{r}0.022 \\
(0.544)\end{array}$ \\
\hline Post-Close $*$ HighUE & $\begin{array}{l}-0.052 \\
(0.310)\end{array}$ & $\begin{array}{c}-0.166 \\
(0.176)\end{array}$ \\
\hline Post-Close $*$ HFT & $\begin{array}{l}-0.015 \\
(0.534)\end{array}$ & $\begin{array}{c}-0.034 \\
(0.412)\end{array}$ \\
\hline HFT * HighUE & $\begin{array}{l}-0.041 \\
(0.392)\end{array}$ & $\begin{array}{c}-0.143 \\
(0.244)\end{array}$ \\
\hline Post-Close $*$ HighUE $*$ HFT & $\begin{array}{r}0.060 \\
(0.126)\end{array}$ & $\begin{array}{r}0.155 \\
(0.109)\end{array}$ \\
\hline Controls (Interacted) & yes & yes \\
\hline \# Observations & 679 & 679 \\
\hline
\end{tabular}


Table 6: HFT and non-HFT trading on low-attention versus high-attention earnings announcements

This table presents univariate tests of the percentage of trading by HFTs on low-attention earnings announcements versus high-attention earnings announcements. HFT ${ }^{\text {All }}$ measures the percentage of trading volume executed by HFTs; HFT ${ }^{D}$ measures the percentage of trading volume in which HFTs demand liquidity; $H F T^{S}$ measures the percentage of trading volume in which HFTs supply liquidity; HN\% measures the percentage of trading volume in which HFTs demand and nonHFTs supply liquidity; and $\mathrm{NH} \%$ measures the percentage of trading volume in which non-HFTs demand and HFTs supply liquidity. Each panel uses a different measure to identify low-attention (first column) versus high-attention (second column) earnings announcements. Panel A compares earnings announcements flagged as high versus low attention under our Aggregate attention metric. Panel B compares earnings announcements that occur on days with above-median number of other earnings announcements (Busy) to those that occur on days with below-median number of other earnings announcements (Quiet). Panel C compares earnings announcements with below-median analyst forecast revision speed (Slow) to those with above-median speed (Fast). Panel D compares earnings announcements that occur on Fridays (Friday) to those that occur on other days of the week (Non-Friday). Panel E compares earnings announcements with above-median number of non-earnings related news (High News Distraction) to those with below-median non-earnings news (Low News Distraction ). Panel F compares earnings announcements with below-median EDGAR download volume (Low EDGAR) to those with above-median download volume (High EDGAR). Panel G compares earnings announcements with below-median Google search volume (Low Google) to those with above-median search volume (High Google).

\begin{tabular}{|c|c|c|c|c|c|c|}
\hline \multicolumn{7}{|c|}{ Panel A: Aggregate low-attention vs high-attention earnings announcements } \\
\hline & Low & High & & Low & High & \\
\hline & Mean & Mean & p-value & $\underline{\text { Median }}$ & Median & $\mathrm{p}$-value \\
\hline $\mathrm{HFT}^{\text {All }}$ & $22.7 \%$ & $18.7 \%$ & 0.0027 & $22.1 \%$ & $17.7 \%$ & 0.0043 \\
\hline $\mathrm{HFT}^{\mathrm{D}}$ & $23.9 \%$ & $21.0 \%$ & 0.0352 & $25.2 \%$ & $20.5 \%$ & 0.0636 \\
\hline $\mathrm{HFT}^{\mathrm{S}}$ & $21.5 \%$ & $16.4 \%$ & 0.0013 & $16.5 \%$ & $13.4 \%$ & 0.0134 \\
\hline HN\% & $17.7 \%$ & $16.7 \%$ & 0.3282 & $19.0 \%$ & $16.8 \%$ & 0.4509 \\
\hline NH\% & $15.3 \%$ & $12.1 \%$ & 0.0051 & $12.1 \%$ & $10.5 \%$ & 0.0328 \\
\hline \# Announcements & 185 & 419 & & 185 & 419 & \\
\hline
\end{tabular}

\begin{tabular}{|c|c|c|c|c|c|c|}
\hline \multicolumn{7}{|c|}{ Panel B: Busy day versus quiet day earnings announcements } \\
\hline & Busy & Quiet & & Busy & Quiet & \\
\hline & Mean & Mean & p-value & Median & Median & p-value \\
\hline $\mathrm{HFT}^{\text {All }}$ & $18.2 \%$ & $20.9 \%$ & 0.0076 & $17.2 \%$ & $19.8 \%$ & 0.0111 \\
\hline $\mathrm{HFT}^{\mathrm{D}}$ & $19.6 \%$ & $23.6 \%$ & 0.0004 & $18.2 \%$ & $24.4 \%$ & 0.0004 \\
\hline $\mathrm{HFT}^{\mathrm{S}}$ & $16.8 \%$ & $18.2 \%$ & 0.2416 & $13.5 \%$ & $14.3 \%$ & 0.1474 \\
\hline HN\% & $15.7 \%$ & $18.4 \%$ & 0.0035 & $15.0 \%$ & $19.1 \%$ & 0.0014 \\
\hline NH\% & $12.9 \%$ & $12.9 \%$ & 0.9973 & $10.3 \%$ & $10.8 \%$ & 0.4842 \\
\hline \# Announcements & 344 & 401 & & 344 & 401 & \\
\hline
\end{tabular}




\begin{tabular}{|c|c|c|c|c|c|c|}
\hline \multicolumn{7}{|c|}{ Panel C: Slow analyst speed versus fast earnings announcements } \\
\hline & Slow & Fast & & Slow & Fast & \\
\hline & $\underline{\text { Mean }}$ & Mean & p-value & $\underline{\text { Median }}$ & $\underline{\text { Median }}$ & p-value \\
\hline HFT $^{\text {All }}$ & $21.2 \%$ & $18.4 \%$ & 0.0103 & $19.8 \%$ & $18.5 \%$ & 0.0260 \\
\hline $\mathrm{HFT}^{\mathrm{D}}$ & $23.1 \%$ & $20.6 \%$ & 0.0436 & $24.2 \%$ & $20.6 \%$ & 0.0546 \\
\hline $\mathrm{HFT}^{\mathrm{S}}$ & $19.4 \%$ & $16.2 \%$ & 0.0112 & $14.3 \%$ & $13.8 \%$ & 0.1494 \\
\hline $\mathrm{HN} \%$ & $17.7 \%$ & $16.3 \%$ & 0.1556 & $17.8 \%$ & $16.7 \%$ & 0.1984 \\
\hline NH\% & $14.0 \%$ & $11.9 \%$ & 0.0240 & $10.9 \%$ & $10.5 \%$ & 0.2710 \\
\hline \# Announcements & 309 & 322 & & 309 & 322 & \\
\hline
\end{tabular}

\begin{tabular}{|c|c|c|c|c|c|c|}
\hline \multicolumn{7}{|c|}{ Panel D: Friday versus non-Friday earnings announcements } \\
\hline & Friday & Non-Frida & & Friday & Non-Friday & \\
\hline & Mean & $\underline{\text { Mean }}$ & p-value & $\underline{\text { Median }}$ & Median & p-value \\
\hline HFT $^{\text {All }}$ & $26.3 \%$ & $19.1 \%$ & 0.0001 & $22.3 \%$ & $18.3 \%$ & 0.0002 \\
\hline $\mathrm{HFT}^{\mathrm{D}}$ & $29.2 \%$ & $21.1 \%$ & 0.0000 & $28.3 \%$ & $21.0 \%$ & 0.0001 \\
\hline $\mathrm{HFT}^{\mathrm{S}}$ & $23.4 \%$ & $17.0 \%$ & 0.0028 & $17.0 \%$ & $13.7 \%$ & 0.0043 \\
\hline HN\% & $21.7 \%$ & $16.7 \%$ & 0.0001 & $21.6 \%$ & $16.6 \%$ & 0.0006 \\
\hline NH\% & $16.0 \%$ & $12.7 \%$ & 0.0377 & $12.1 \%$ & $10.4 \%$ & 0.0240 \\
\hline \# Announcements & 60 & 685 & & 60 & 685 & \\
\hline
\end{tabular}

Panel E: High versus low news distraction earnings announcements

\begin{tabular}{|c|c|c|c|c|c|c|}
\hline & High distraction & Low distraction & & High distraction & Low distraction & \\
\hline & Mean & Mean & p-value & $\underline{\text { Median }}$ & $\underline{\text { Median }}$ & p-value \\
\hline $\mathrm{HFT}^{\text {All }}$ & $24.0 \%$ & $16.5 \%$ & 0.0000 & $23.3 \%$ & $16.4 \%$ & 0.0000 \\
\hline $\mathrm{HFT}^{\mathrm{D}}$ & $25.6 \%$ & $18.9 \%$ & 0.0000 & $26.2 \%$ & $17.1 \%$ & 0.0000 \\
\hline $\mathrm{HFT}^{\mathrm{S}}$ & $22.3 \%$ & $14.0 \%$ & 0.0000 & $17.8 \%$ & $11.6 \%$ & 0.0000 \\
\hline HN\% & $19.1 \%$ & $15.6 \%$ & 0.0001 & $19.2 \%$ & $14.9 \%$ & 0.0001 \\
\hline NH\% & $15.8 \%$ & $10.8 \%$ & 0.0000 & $13.4 \%$ & $9.2 \%$ & 0.0000 \\
\hline \# Announcements & 317 & 428 & & 317 & 428 & \\
\hline
\end{tabular}

\begin{tabular}{|c|c|c|c|c|c|c|}
\hline \multicolumn{7}{|c|}{ Panel F: Low versus high EDGAR download earnings announcements } \\
\hline & Low EDGAR & High EDGAR & & Low EDGAR & High EDGAR & \\
\hline & Mean & Mean & p-value & $\underline{\text { Median }}$ & $\underline{\text { Median }}$ & p-value \\
\hline $\mathrm{HFT}^{\mathrm{All}}$ & $19.6 \%$ & $19.9 \%$ & 0.8286 & $18.2 \%$ & $19.1 \%$ & 0.7325 \\
\hline $\mathrm{HFT}^{\mathrm{D}}$ & $21.2 \%$ & $22.5 \%$ & 0.3050 & $21.2 \%$ & $22.9 \%$ & 0.3094 \\
\hline $\mathrm{HFT}^{\mathrm{S}}$ & $18.0 \%$ & $17.3 \%$ & 0.5288 & $14.3 \%$ & $13.5 \%$ & 0.8178 \\
\hline HN\% & $16.5 \%$ & $17.9 \%$ & 0.1300 & $16.6 \%$ & $17.9 \%$ & 0.1704 \\
\hline NH\% & $13.3 \%$ & $12.7 \%$ & 0.5403 & $10.9 \%$ & $10.4 \%$ & 0.7478 \\
\hline \# Announcements & 350 & 353 & & 350 & 353 & \\
\hline
\end{tabular}




\begin{tabular}{lcccccc}
\hline \multicolumn{7}{l}{ Panel G: Low versus high Google search earnings announcements } \\
\hline & Low & High & & Low & High \\
& $\underline{\text { Mean }}$ & $\underline{\text { Mean }}$ & p-value & $\underline{\text { Median }}$ & $\underline{\text { Median }}$ & p-value \\
HFT $^{\text {All }}$ & $20.7 \%$ & $20.4 \%$ & 0.8335 & $19.8 \%$ & $19.6 \%$ & 0.8883 \\
$\mathrm{HFT}^{\mathrm{D}}$ & $23.5 \%$ & $22.9 \%$ & 0.6511 & $24.7 \%$ & $23.8 \%$ & 0.5803 \\
$\mathrm{HFT}^{S}$ & $17.9 \%$ & $18.0 \%$ & 0.9361 & $14.5 \%$ & $14.0 \%$ & 0.9185 \\
$\mathrm{HN}^{S}$ & $18.4 \%$ & $18.1 \%$ & 0.8344 & $18.0 \%$ & $18.9 \%$ & 0.5840 \\
NH\% & $12.8 \%$ & $13.3 \%$ & 0.5895 & $10.9 \%$ & $11.3 \%$ & 0.4616 \\
\# Announcements & 216 & 219 & & 216 & 219 & \\
\hline
\end{tabular}




\section{Table 7: HFT demand versus supply and price efficiency}

This table presents multivariate tests of price efficiency with versus without abnormal HFT demand versus supply. The dependent variable is the cumulative abnormal return (CAR) for stock $i$ on earnings announcement days $t$ and $t+1$ in the first column and day $t+2$ to $t+45$ in the second column; cumulative abnormal return is expressed in decimal form, so 0.01 equals $1 \%$. Low Attention is equal to one if the earnings announcement falls into the low-attention category under the Aggregate measure, which reflects the combined distribution of Friday, Busy Day, Slow Analyst Speed, High News Distraction, and Low EDGAR earnings announcements. $H F T^{D-S}$ is equal to one if HFT shares demanded minus supplied for stock $i$ on earnings announcement day $t$ is greater than the median for stock $i$ on non-earningsannouncement days, else zero; HighUE is equal to one if the announcement has above-median unexpected earnings, else zero. Regressions also include as controls market capitalization and earnings surprise volatility over the prior four years and month and year indicators. All controls are also interacted with HighUE; the intercept, controls, and interacted controls are not reported. P-values (reported in parentheses below coefficient estimates) are based on standard errors that are clustered by announcement day. ${ }^{*}, * *$, and $* * *$ denote significance at the $10 \%, 5 \%$, and $1 \%$ levels.

\begin{tabular}{|c|c|c|}
\hline Dependent variable & $\begin{array}{c}\text { CAR on } \\
\text { earnings announcement } \\
\text { days } t \text { to } t+1 \\
\end{array}$ & $\begin{array}{c}\text { CAR on } \\
\text { earnings announcement } \\
\text { days } t+2 \text { to } t+45 \\
\end{array}$ \\
\hline Low Attention & $\begin{array}{r}0.019 \\
(0.164)\end{array}$ & $\begin{array}{l}-0.017 \\
(0.297)\end{array}$ \\
\hline HighUE & $\begin{array}{l}-0.002 \\
(0.969)\end{array}$ & $\begin{array}{r}0.010 \\
(0.920)\end{array}$ \\
\hline $\mathrm{HFT}^{\mathrm{D}-\mathrm{S}}$ & $\begin{array}{r}0.002 \\
(0.860)\end{array}$ & $\begin{array}{r}0.010 \\
(0.604)\end{array}$ \\
\hline Low Attention * HighUE & $\begin{array}{l}-0.035 * \\
(0.079)\end{array}$ & $\begin{array}{l}0.063 * * \\
(0.019)\end{array}$ \\
\hline Low Attention * $\mathrm{HFT}^{\mathrm{D}-\mathrm{s}}$ & $\begin{array}{l}-0.009 \\
(0.619)\end{array}$ & $\begin{array}{r}0.003 \\
(0.937)\end{array}$ \\
\hline $\mathrm{HFT}^{\mathrm{D}-\mathrm{S}} *$ HighUE & $\begin{array}{r}0.006 \\
(0.725)\end{array}$ & $\begin{array}{l}-0.003 \\
(0.921)\end{array}$ \\
\hline Low Attention $*$ HighUE $*$ HFT $^{\text {D-S }}$ & $\begin{array}{l}0.053 * * \\
(0.032)\end{array}$ & $\begin{array}{l}-0.064 * \\
(0.067)\end{array}$ \\
\hline Controls (Interacted) & yes & yes \\
\hline \# Observations & 576 & 576 \\
\hline
\end{tabular}




\section{Table 8: HFT and price efficiency for small versus large firms}

This table presents multivariate tests of price efficiency with versus without HFT. The dependent variable is the cumulative abnormal return (CAR) for stock $i$ on earnings announcement days $t$ and $t+1$ in Panel A and day $t+2$ to t+45 in Panel B; cumulative abnormal return is expressed in decimal form, so 0.01 equals $1 \%$. Small Firms (Large Firms) are defined as firms with below-median (above-median) market capitalization.Low Attention is equal to one if the earnings announcement falls into the low-attention category under the Aggregate measure, which reflects the combined distribution of Friday, Busy Day, Slow Analyst Speed, High News Distraction, and Low EDGAR earnings announcements. HFT is equal to one if there is high-frequency trading in the rest of the day following the earnings announcement, else zero; HighUE is equal to one if the announcement has above-median unexpected earnings, else zero. Regressions also include as controls market capitalization and earnings surprise volatility over the prior four years and month and year indicators. All controls are also interacted with HighUE; the intercept, controls, and interacted controls are not reported. P-values (reported in parentheses below coefficient estimates) are based on standard errors that are clustered by announcement day. *, **, and *** denote significance at the $10 \%, 5 \%$, and $1 \%$ levels.

Panel A: Cumulative abnormal return (CAR) on earnings announcement days $t$ to $t+1$

Low Attention

$$
\begin{gathered}
0.080 * * \\
(0.027)
\end{gathered}
$$

HighUE

$-0.114 *$

0.038

(0.056)

(0.681)

HFT

$-0.001$

$-0.056$

(0.944)

(0.142)

Low Attention * HighUE

$-0.150 * * *$

0.021

(0.003)

(0.783)

Low Attention * HFT

$-0.053$

0.050

(0.194)

(0.296)

HFT * HighUE

$-0.011$

0.044

(0.719)

(0.511)

Low Attention * HighUE * HFT

$0.172 * * *$

$-0.025$

(0.002)

(0.377)

Controls (Interacted)

yes 
Panel B: Cumulative abnormal return (CAR) on earnings announcement days $t+2$ to $t+45$

Low Attention

$-0.071$

(0.293)

$-0.106 * *$

0.011

(0.941)

0.030

(0.440)

$0.268 * * *$

(0.004)

0.070

(0.424)

0.045

(0.418)

$-0.280 * * *$

(0.006)

yes

276
(0.023)

$-0.013$

(0.902)

$-0.052$

(0.198)

0.078

(0.330)

0.086 *

(0.083)

$-0.016$

(0.813)

$-0.034$

(0.342)

yes
300

\# Observations 


\section{Table 9: HFT and Short-term price efficiency with 1-day and 3-day horizons}

This table presents multivariate tests of price efficiency with versus without HFT. The dependent variable is the cumulative abnormal return for stock on earnings announcement day $t$ in Panel A days $t-1$ to $t+1$ in Panel B; cumulative abnormal return is expressed in decimal form, so 0.01 equals $1 \%$ Low Attention is equal to one if the earnings announcement falls into the low-attention category given the proxy being used, else zero;Aggregate reflects the combined distribution of Friday, Busy Day, Slow Analyst Speed, High News Distraction, and Low EDGAR earnings announcements. HFT is equal to one if there is high-frequency trading in the rest of the day following the earnings announcement, else zeroHighUE is equal to one if the announcement has abovemedian unexpected earnings, else zero. Regressions also include as controls market capitalization and earnings surprise volatility over the prior four years and month and year indicators. All controls are also interacted with HighUE; the intercept, controls, and interacted controls are not reported. P-values (reported in parentheses below coefficient estimates) are based on standard errors that are clustered by announcement day. *, **, and *** denote significance at the $10 \%$, $5 \%$, and $1 \%$ levels.

\section{Panel A: One-day Cumulative Abnormal Return}

Dependent variable $=$ Cumulative abnormal return (CAR) on earnings announcement dayst

\begin{tabular}{|c|c|c|c|c|c|c|}
\hline Low Attention proxy & Aggregate & Busy Day & $\begin{array}{l}\text { Slow Analyst } \\
\text { Speed }\end{array}$ & $\begin{array}{l}\text { High News } \\
\text { Distraction }\end{array}$ & Low EDGAR & $\begin{array}{l}\text { Low Google } \\
\text { Search }\end{array}$ \\
\hline Low Attention & $\begin{array}{r}0.010 \\
(0.505)\end{array}$ & $\begin{array}{r}0.013 \\
(0.199)\end{array}$ & $\begin{array}{r}0.009 \\
(0.465)\end{array}$ & $\begin{array}{r}0.006 \\
(0.681)\end{array}$ & $\begin{array}{l}-0.001 \\
(0.939)\end{array}$ & $\begin{array}{r}0.014 \\
(0.393)\end{array}$ \\
\hline HighUE & $\begin{array}{l}-0.015 \\
(0.667)\end{array}$ & $\begin{array}{l}-0.018 \\
(0.574)\end{array}$ & $\begin{array}{l}-0.008 \\
(0.811)\end{array}$ & $\begin{array}{l}-0.038 \\
(0.246)\end{array}$ & $\begin{array}{l}-0.010 \\
(0.773)\end{array}$ & $\begin{array}{r}0.034 \\
(0.517)\end{array}$ \\
\hline HFT & $\begin{array}{l}-0.018 * * \\
(0.031)\end{array}$ & $\begin{array}{l}-0.019 * * \\
(0.020)\end{array}$ & $\begin{array}{l}-0.014 \\
(0.129)\end{array}$ & $\begin{array}{l}-0.016 * * \\
(0.025)\end{array}$ & $\begin{array}{l}-0.022 * * * \\
(0.008)\end{array}$ & $\begin{array}{l}-0.041 * * * \\
(0.004)\end{array}$ \\
\hline Low Attention * HighUE & $\begin{array}{c}-0.034 \\
(0.121)\end{array}$ & $\begin{array}{l}-0.035 * \\
(0.068)\end{array}$ & $\begin{array}{l}-0.036 * \\
(0.076)\end{array}$ & $\begin{array}{l}-0.018 \\
(0.382)\end{array}$ & $\begin{array}{l}-0.022 \\
(0.229)\end{array}$ & $\begin{array}{l}-0.024 \\
(0.414)\end{array}$ \\
\hline Low Attention * HFT & $\begin{array}{c}-0.008 \\
(0.625)\end{array}$ & $\begin{array}{r}0.000 \\
(0.985)\end{array}$ & $\begin{array}{l}-0.016 \\
(0.237)\end{array}$ & $\begin{array}{l}-0.017 \\
(0.246)\end{array}$ & $\begin{array}{r}0.010 \\
(0.316)\end{array}$ & $\begin{array}{r}0.002 \\
(0.918)\end{array}$ \\
\hline HFT $*$ HighUE & $\begin{array}{r}0.016 \\
(0.265)\end{array}$ & $\begin{array}{r}0.009 \\
(0.604)\end{array}$ & $\begin{array}{r}0.010 \\
(0.536)\end{array}$ & $\begin{array}{r}0.016 \\
(0.216)\end{array}$ & $\begin{array}{r}0.006 \\
(0.761)\end{array}$ & $\begin{array}{r}0.042 \\
(0.118)\end{array}$ \\
\hline Low Attention * HighUE * HFT & $\begin{array}{l}0.047 \text { ** } \\
(0.026)\end{array}$ & $\begin{array}{c}0.026 * \\
(0.089)\end{array}$ & $\begin{array}{l}0.039 * * \\
(0.042)\end{array}$ & $\begin{array}{l}0.029 * \\
(0.093)\end{array}$ & $\begin{array}{r}0.025 \\
(0.115)\end{array}$ & $\begin{array}{r}0.003 \\
(0.469)\end{array}$ \\
\hline Controls (Interacted) & yes & yes & yes & yes & yes & yes \\
\hline \# Observations & 576 & 679 & 603 & 679 & 642 & 398 \\
\hline
\end{tabular}


Panel B: Three-day Cumulative Abnormal Return

\begin{tabular}{|c|c|c|c|c|c|c|}
\hline Low Attention proxy & Aggregate & Busy Day & $\begin{array}{l}\text { Slow Analyst } \\
\text { Speed }\end{array}$ & $\begin{array}{l}\text { High News } \\
\text { Distraction }\end{array}$ & Low EDGAR & $\begin{array}{c}\text { Low Google } \\
\text { Search }\end{array}$ \\
\hline Low Attention & $\begin{array}{l}0.098 * * * \\
(0.003)\end{array}$ & $\begin{array}{c}0.052 * \\
(0.073)\end{array}$ & $\begin{array}{r}0.030 \\
(0.336)\end{array}$ & $\begin{array}{l}-0.013 \\
(0.682)\end{array}$ & $\begin{array}{r}0.042 \\
(0.112)\end{array}$ & $\begin{array}{r}0.055 \\
(0.214)\end{array}$ \\
\hline HighUE & $\begin{array}{l}-0.002 \\
(0.971)\end{array}$ & $\begin{array}{l}-0.023 \\
(0.644)\end{array}$ & $\begin{array}{l}-0.015 \\
(0.735)\end{array}$ & $\begin{array}{l}-0.085 * \\
(0.058)\end{array}$ & $\begin{array}{l}-0.023 \\
(0.704)\end{array}$ & $\begin{array}{l}-0.047 \\
(0.549)\end{array}$ \\
\hline HFT & $\begin{array}{c}0.037 * \\
(0.083)\end{array}$ & $\begin{array}{r}0.019 \\
(0.384)\end{array}$ & $\begin{array}{r}0.022 \\
(0.264)\end{array}$ & $\begin{array}{r}0.008 \\
(0.673)\end{array}$ & $\begin{array}{r}0.032 \\
(0.140)\end{array}$ & $\begin{array}{r}0.021 \\
(0.636)\end{array}$ \\
\hline Low Attention * HighUE & $\begin{array}{l}-0.166 * * * \\
(0.001)\end{array}$ & $\begin{array}{l}-0.110 * * \\
(0.017)\end{array}$ & $\begin{array}{l}-0.070 \\
(0.159)\end{array}$ & $\begin{array}{l}-0.008 \\
(0.895)\end{array}$ & $\begin{array}{c}-0.073 \\
(0.138)\end{array}$ & $\begin{array}{l}-0.027 \\
(0.685)\end{array}$ \\
\hline Low Attention * HFT & $\begin{array}{l}-\mathbf{0 . 0 9 8} * * * \\
(0.005)\end{array}$ & $\begin{array}{l}-0.025 \\
(0.385)\end{array}$ & $\begin{array}{l}-0.034 \\
(0.312)\end{array}$ & $\begin{array}{l}-0.003 \\
(0.927)\end{array}$ & $\begin{array}{l}-0.040 \\
(0.152)\end{array}$ & $\begin{array}{l}-0.061 \\
(0.191)\end{array}$ \\
\hline HFT * HighUE & $\begin{array}{l}-0.033 \\
(0.329)\end{array}$ & $\begin{array}{l}-0.030 \\
(0.404)\end{array}$ & $\begin{array}{l}-0.011 \\
(0.748)\end{array}$ & $\begin{array}{r}0.006 \\
(0.839)\end{array}$ & $\begin{array}{l}-0.032 \\
(0.475)\end{array}$ & $\begin{array}{r}0.024 \\
(0.714)\end{array}$ \\
\hline Low Attention * HighUE * HFT & $\begin{array}{c}0.183 \\
(<.001)\end{array}$ & $\begin{array}{c}0.087^{* *} \\
(0.028)\end{array}$ & $\begin{array}{c}0.070 * \\
(0.100)\end{array}$ & $\begin{array}{r}0.034 \\
(0.293)\end{array}$ & $\begin{array}{c}0.083 * \\
(0.054)\end{array}$ & $\begin{array}{r}0.031 \\
(0.333)\end{array}$ \\
\hline Controls (Interacted) & yes & yes & yes & yes & yes & yes \\
\hline \# Observations & 576 & 679 & 603 & 679 & 642 & 398 \\
\hline
\end{tabular}




\section{Table 10: HFT and Long-term price efficiency with 30-day horizon}

2 days after earnings announcement day $t$ to 30 days after; cumulative abnormal return is expressed in decimal form, so 0.01 equals $1 \%$. Low Attention is equal to one if the earnings announcement falls into the low-attention category given the proxy being used, else zero; Aggregate reflects the combined distribution of Friday, Busy Day, Slow Analyst Speed, High News Distraction, and Low EDGAR earnings announcements. HFT is equal to one if there is high-frequency trading in the rest of the day following the earnings announcement, else zero; HighUE is equal to one if the announcement has abovemedian unexpected earnings, else zero. Regressions also include as controls market capitalization and earnings surprise volatility over the prior four years and month and year indicators. All controls are also interacted with HighUE; the intercept, controls, and interacted controls are not reported. P-values (reported below coefficient estimates) are based on standard errors that are clustered by announcement day. *, **, and *** denote significance at the $10 \%$, $5 \%$, and $1 \%$ levels.

\begin{tabular}{|c|c|c|c|c|c|c|}
\hline \multicolumn{7}{|c|}{ Dependent variable $=$ Cumulative abnormal return (CAR) on post-earnings-announcement days $t+2$ to $t+30$} \\
\hline Low Attention proxy & Aggregate & Busy Day & $\begin{array}{c}\text { Slow Analyst } \\
\text { Speed }\end{array}$ & $\begin{array}{l}\text { High News } \\
\text { Distraction }\end{array}$ & Low EDGAR & $\begin{array}{c}\text { Low Google } \\
\text { Search } \\
\end{array}$ \\
\hline Low Attention & $\begin{array}{l}-0.016 \\
(0.573)\end{array}$ & $\begin{array}{l}-0.021 \\
(0.496)\end{array}$ & $\begin{array}{r}0.009 \\
(0.782)\end{array}$ & $\begin{array}{l}-0.008 \\
(0.872)\end{array}$ & $\begin{array}{l}-0.031 \\
(0.398)\end{array}$ & $\begin{array}{r}0.011 \\
(0.748)\end{array}$ \\
\hline HighUE & $\begin{array}{r}0.008 \\
(0.922)\end{array}$ & $\begin{array}{r}0.045 \\
(0.576)\end{array}$ & $\begin{array}{r}0.017 \\
(0.815)\end{array}$ & $\begin{array}{r}0.06 \\
(0.409)\end{array}$ & $\begin{array}{l}-0.057 \\
(0.473)\end{array}$ & $\begin{array}{r}0.064 \\
(0.487)\end{array}$ \\
\hline HFT & $\begin{array}{r}0.002 \\
(0.894)\end{array}$ & $\begin{array}{l}-0.033 \\
(0.183)\end{array}$ & $\begin{array}{r}0.011 \\
(0.542)\end{array}$ & $\begin{array}{l}-0.018 \\
(0.310)\end{array}$ & $\begin{array}{l}-0.022 \\
(0.502)\end{array}$ & $\begin{array}{c}0.064 * \\
(0.098)\end{array}$ \\
\hline Low Attention * HighUE & $\begin{array}{l}0.172 * * * \\
(<.001)\end{array}$ & $\begin{array}{r}0.053 \\
(0.280)\end{array}$ & $\begin{array}{c}0.102 * \\
(0.058)\end{array}$ & $\begin{array}{r}0.092 \\
(0.136)\end{array}$ & $\begin{array}{l}0.152 \text { *** } \\
(0.005)\end{array}$ & $\begin{array}{r}0.090 \\
(0.153)\end{array}$ \\
\hline Low Attention * HFT & $\begin{array}{r}0.002 \\
(0.962)\end{array}$ & $\begin{array}{r}0.031 \\
(0.356)\end{array}$ & $\begin{array}{l}-0.023 \\
(0.501)\end{array}$ & $\begin{array}{r}0.009 \\
(0.866)\end{array}$ & $\begin{array}{r}0.015 \\
(0.707)\end{array}$ & $\begin{array}{l}-0.031 \\
(0.415)\end{array}$ \\
\hline HFT * HighUE & $\begin{array}{r}0.037 \\
(0.228)\end{array}$ & $\begin{array}{r}0.039 \\
(0.345)\end{array}$ & $\begin{array}{r}0.040 \\
(0.277)\end{array}$ & $\begin{array}{r}0.019 \\
(0.534)\end{array}$ & $\begin{array}{r}0.079 \\
(0.108)\end{array}$ & $\begin{array}{l}-0.018 \\
(0.764)\end{array}$ \\
\hline Low Attention * HighUE $*$ HFT & $\begin{array}{l}-0.148 * * * \\
(0.002)\end{array}$ & $\begin{array}{l}-0.068 * \\
(0.094)\end{array}$ & $\begin{array}{l}-0.085 * \\
(0.066)\end{array}$ & $\begin{array}{l}-0.08 * \\
(0.099)\end{array}$ & $\begin{array}{l}-0.116 * * \\
(0.021)\end{array}$ & $\begin{array}{l}-0.081 \\
(0.113)\end{array}$ \\
\hline Controls (Interacted) & yes & yes & yes & yes & yes & yes \\
\hline \# Observations & 576 & 679 & 603 & 679 & 642 & 398 \\
\hline
\end{tabular}




\section{Table 11: HFTs and price efficiency under alternative HFT cutoffs}

This table presents multivariate tests of price efficiency with versus without HFT using two alternative cutoff points. Panel A indentifies events with HFT trading if HFT trading exceeds $5 \%$ of trading volume. Panel B indentifies events with HFT trading if HFTs trade within 2 hours from earnings announcement time. The dependent variable is the cumulative abnormal return (CAR) for stock $i$ on earnings announcement days $t$ and $t+1$ in the first column and day $t+2$ to $t+45$ in the second column; cumulative abnormal return is expressed in decimal form, so 0.01 equals $1 \%$. Low Attention is equal to one if the earnings announcement falls into the low-attention category under the Aggregate measure, which reflects the combined distribution of Friday, Busy Day, Slow Analyst Speed, High News

Distraction, and Low EDGAR earnings announcements. HFT ${ }^{5 \%}$ is equal to one if HFT trading exceeds $5 \%$ of trading volume after earnings announcment time for stock $i$ on earnings announcement day $t$, else zero; $\mathrm{HFT}^{2 \text { hour }}$ is equal to one if HFTs trade within 2 hours from earnings announcement time for stock i on earnings announcement day t, else zero; HighUE is equal to one if the announcement has abovemedian unexpected earnings, else zero. Regressions also include as controls market capitalization and earnings surprise volatility over the prior four years and month and year indicators. All controls are also interacted with HighUE; the intercept, controls, and interacted controls are not reported. P-values (reported in parentheses below coefficient estimates) are based on standard errors that are clustered by announcement day. ${ }^{*}, *$, and $* * *$ denote significance at the $10 \%, 5 \%$, and $1 \%$ levels.

Panel A: HFTs trade more than $5 \%$ of the trading volume

\begin{tabular}{|c|c|c|}
\hline Dependent variable & $\begin{array}{c}\text { CAR on } \\
\text { earnings announcement } \\
\text { days } t \text { to } t+1 \\
\end{array}$ & $\begin{array}{c}\text { CAR on } \\
\text { earnings announcement } \\
\text { days } t+2 \text { to } t+45 \\
\end{array}$ \\
\hline Low Attention & $\begin{array}{l}0.051 * * \\
(0.040)\end{array}$ & $\begin{array}{l}-0.031 \\
(0.317)\end{array}$ \\
\hline HighUE & $\begin{array}{r}0.014 \\
(0.753)\end{array}$ & $\begin{array}{r}0.038 \\
(0.710)\end{array}$ \\
\hline $\mathrm{HFT}^{5 \%}$ & $\begin{array}{l}0.030 * \\
(0.079)\end{array}$ & $\begin{array}{r}0.011 \\
(0.628)\end{array}$ \\
\hline Low Attention * HighUE & $\begin{array}{l}-0.090 * * \\
(0.024)\end{array}$ & $\begin{array}{l}0.178 * * * \\
(<.001)\end{array}$ \\
\hline Low Attention * $\mathrm{HFT}^{5 \%}$ & $\begin{array}{l}-0.043 \\
(0.128)\end{array}$ & $\begin{array}{r}0.019 \\
(0.597)\end{array}$ \\
\hline $\mathrm{HFT}^{5 \%} *$ HighUE & $\begin{array}{l}-0.036 \\
(0.104)\end{array}$ & $\begin{array}{r}0.010 \\
(0.783)\end{array}$ \\
\hline Low Attention * HighUE * HFT $^{5 \%}$ & $\begin{array}{l}0.094^{* *} \\
(0.015)\end{array}$ & $\begin{array}{l}-0.175 * * * \\
(0.001)\end{array}$ \\
\hline Controls (Interacted) & yes & yes \\
\hline \# Observations & 576 & 576 \\
\hline
\end{tabular}


Panel B: HFTs trade within 2 hours after announcement time

\begin{tabular}{|c|c|c|}
\hline Dependent variable & $\begin{array}{c}\text { CAR on } \\
\text { earnings announcement } \\
\text { days } t \text { to } t+1 \\
\end{array}$ & $\begin{array}{c}\text { CAR on } \\
\text { earnings announcement } \\
\text { days } t+2 \text { to } t+45\end{array}$ \\
\hline Low Attention & $\begin{array}{r}0.024 \\
(0.112)\end{array}$ & $\begin{array}{l}-0.033 \\
(0.359)\end{array}$ \\
\hline HighUE & $\begin{array}{l}-0.024 \\
(0.587)\end{array}$ & $\begin{array}{r}0.019 \\
(0.853)\end{array}$ \\
\hline $\mathrm{HFT}^{2 \text { hour }}$ & $\begin{array}{r}0.007 \\
(0.598)\end{array}$ & $\begin{array}{l}-0.007 \\
(0.777)\end{array}$ \\
\hline Low Attention * HighUE & $\begin{array}{l}-0.049 * * \\
(0.032)\end{array}$ & $\begin{array}{c}0.100 * \\
(0.050)\end{array}$ \\
\hline Low Attention * $\mathrm{HFT}^{2 \text { hour }}$ & $\begin{array}{l}-0.013 \\
(0.505)\end{array}$ & $\begin{array}{r}0.022 \\
(0.555)\end{array}$ \\
\hline HFT $^{2 \text { hour }} *$ HighUE & $\begin{array}{r}0.005 \\
(0.797)\end{array}$ & $\begin{array}{r}0.014 \\
(0.669)\end{array}$ \\
\hline Low Attention $*$ HighUE $*$ HFT $^{2 \text { hour }}$ & $\begin{array}{l}0.060 * * \\
(0.015)\end{array}$ & $\begin{array}{l}-0.100 * * \\
(0.039)\end{array}$ \\
\hline Controls (Interacted) & yes & yes \\
\hline \# Observations & 576 & 576 \\
\hline
\end{tabular}




\section{Figure 1: HFT effects on short-horizon cumulative abnormal returns}

This graph depicts the marginal effects on post-earnings-announcement days $t$ to $t+1$, comparing the coefficients of interest from regressions in Table 3. Low Attention * High UE is the classic low-atteniton effect, and Low Attention * High UE* HFT is the marginal effect of HFT trading on low attention high-earnings-surprise announcements. Asterisks following the low-attention proxy labels indicate that the marginal effect of HFT is significant at the $1 \%(* * *), 5 \%(* *)$, or $10 \%(*)$ level.

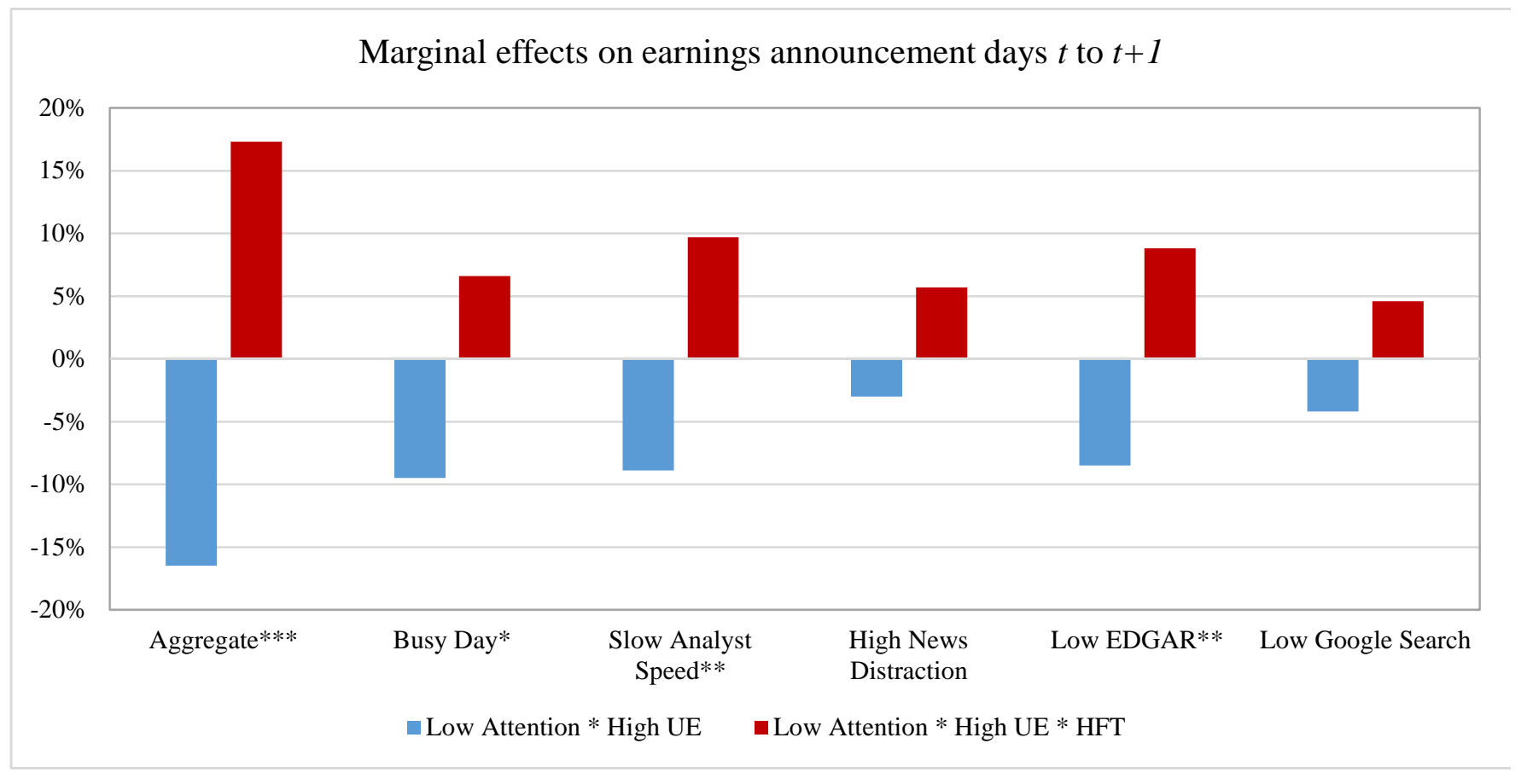


Figure 2: HFT effects on long-horizon cumulative abnormal returns

This graph depicts the marginal effects on post-earnings-announcement days $t+2$ to $t+45$, comparing the coefficients of interest from regressions in Table 4. Low Attention * High UE is the classic low-atteniton effect, and Low Attention * High UE * HFT is the marginal effect of HFT trading on low attention high-earningssurprise announcements. Asterisks following the low-attention proxy labels indicate that the marginal effect of HFT is significant at the $1 \%(* * *), 5 \%(* *)$, or $10 \%(*)$ level.

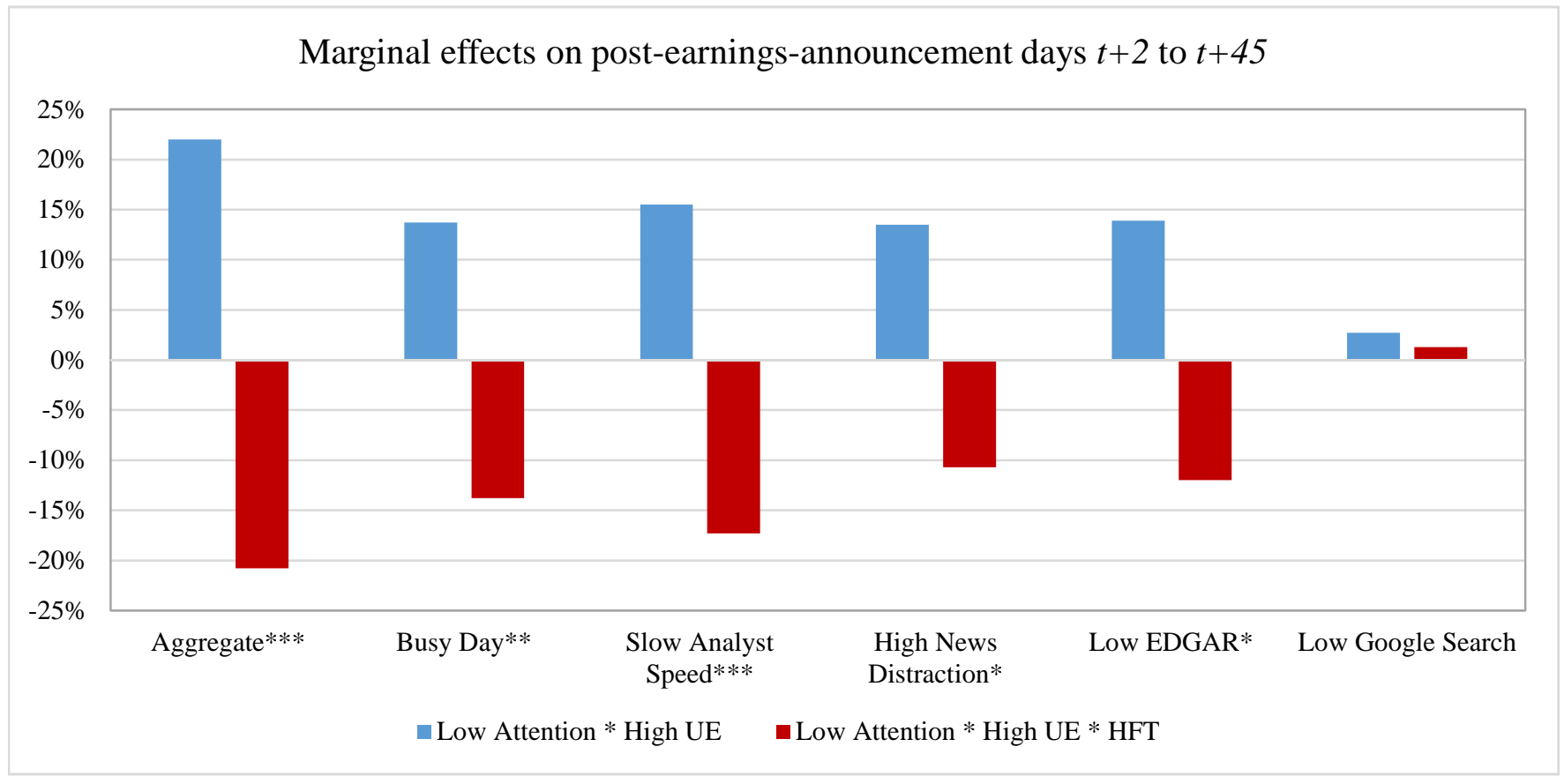

